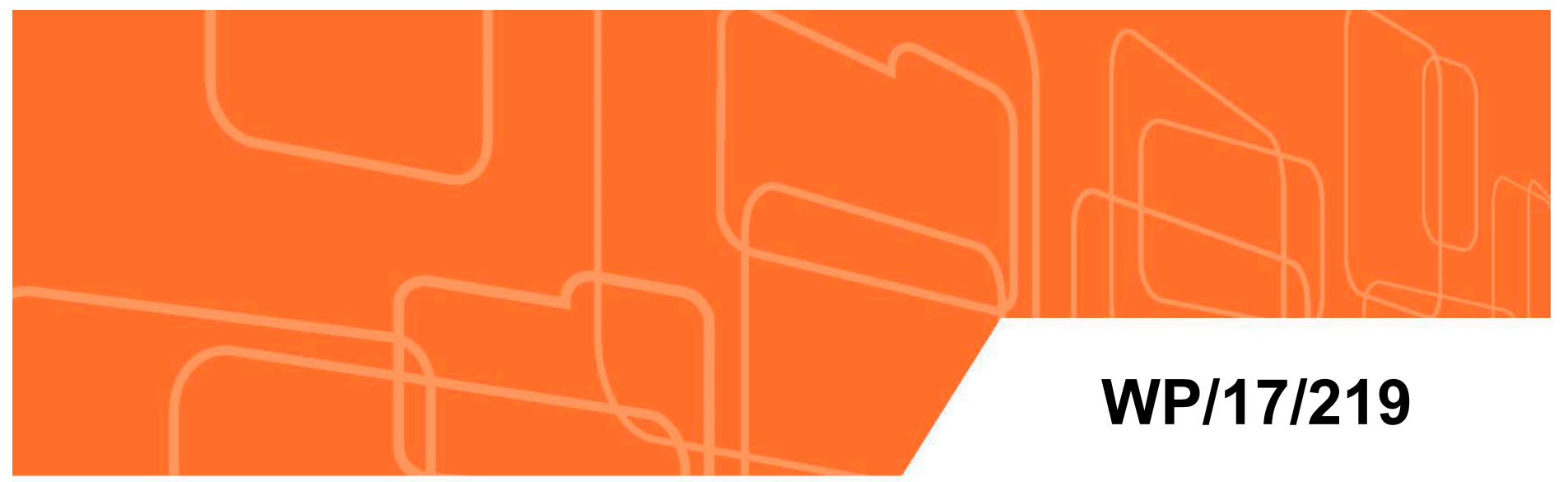

\title{
Measuring Global and Country-Specific Uncertainty
}

by Ezgi O. Ozturk and Xuguang Simon Sheng (American University)

IMF Working Papers describe research in progress by the author(s) and are published to elicit comments and to encourage debate. The views expressed in IMF Working Papers are those of the author(s) and do not necessarily represent the views of the IMF, its Executive Board, or IMF management. 


\title{
IMF Working Paper
}

Finance Department

\section{Measuring Global and Country-specific Uncertainty \\ Prepared by Ezgi O. Ozturk and Xuguang Simon Sheng}

Authorized for distribution by Donal McGettigan

October 2017

\section{IMF Working Papers describe research in progress by the author(s) and are published to elicit comments and to encourage debate. The views expressed in IMF Working Papers are those of the author(s) and do not necessarily represent the views of the IMF, its Executive Board, or IMF management.}

\begin{abstract}
Motivated by the literature on the capital asset pricing model, we decompose the uncertainty of a typical forecaster into common and idiosyncratic uncertainty. Using individual survey data from the Consensus Forecasts over the period of 1989-2014, we develop monthly measures of macroeconomic uncertainty covering 45 countries and construct a measure of global uncertainty as the weighted average of country-specific uncertainties. Our measure captures perceived uncertainty of market participants and derives from two components that are shown to exhibit strikingly different behavior. Common uncertainty shocks produce the large and persistent negative response in real economic activity, whereas the contributions of idiosyncratic uncertainty shocks are negligible.
\end{abstract}

JEL Classification Numbers: E24; E32

Keywords: Capital Asset Pricing Model; Common Uncertainty; Consensus Forecasts; Idiosyncratic Uncertainty; Global Uncertainty; Survey Forecast

Authors' E-Mail Addresses: eozturk@,imf.org; sheng@american.edu 


\section{Introduction}

Heightened economic uncertainty, at both national and global levels, greatly contributed to the 2007-09 recession and shaped the speed of the subsequent recovery. Eight years after the end of the recession, there is still no sign of a complete global recovery. Advanced economies are uncertain about the effects of monetary policy normalization and emerging market economies are uncertain about the growth challenges ahead. Surrounded with unprecedentedly high uncertainty, economists face great challenges in understanding the origins of economic uncertainty and analyzing its causal impacts on real economy, e.g. Stock and Watson (2012).

Since there is no objective measure of uncertainty, economists have used numerous different proxies. A ubiquitous proxy is the implied or realized volatility in stock markets, such as VIX, e.g. Bloom (2009). However, the volatility in Wall Street might not reflect uncertainty in Main Street. For instance, changes in the VIX might be due to leverage or financial stress, despite low levels of economic uncertainty; see Bekaert et al. (2013). Jurado, et al. (2015) develop an alternative measure of economic uncertainty: the common variation in uncertainty across hundreds of economic series. Their measure reflects uncertainty around objective statistical forecasts, rather than perceived uncertainty by market participants. Moreover, as they focus on common, not idiosyncratic, uncertainty, there is no role for private information and heterogeneous agent models. A third leading proxy is based on the frequency of references to policy-related uncertainty in the newspapers, e.g. Baker, et al. (2016). But, like all measurements of this type, this news-based uncertainty measure puts a high bar for the attentiveness of reporters and editors, who might miss uncertainty events if they neglect to write a story on the subject. The fourth proxy for uncertainty is cross-sectional disagreement 
of economic agents, calculated as the dispersion in directional or point forecasts, e.g. Bachmann et al. (2013). When disagreement is taken to indicate uncertainty, the underlying assumption is that this inter-personal dispersion measure is an acceptable proxy for the average dispersion of intra-personal uncertainty. As shown by Lahiri and Sheng (2010), however, disagreement is only a part of uncertainty and misses an important component: the volatility of aggregate shocks.

To address some of the limitations in the existing measures, we develop a comprehensive measure of economic uncertainty by incorporating rich information reflected in the surveys of professional forecasters. Similar to Jo and Sekkel (2015), Rossi and Sekhposyan (2015) and Scotti (2016), our measure is based on subjective forecasts of market participants and reflects their perceived uncertainty. In contrast to these three papers, our uncertainty measure includes two components: common uncertainty as emphasized in Jurado et al. (2015) and idiosyncratic uncertainty as documented in the macroeconomics literature. Our decomposition of uncertainty of a typical forecaster into common and idiosyncratic parts is similar to Campbell et al. (2001) that decompose the volatility of a typical stock into market and firm-level volatility. We estimate the common component as the perceived variability of future aggregate shocks and idiosyncratic component as the disagreement among professional forecasters across three different layers. First, we estimate the variable-specific uncertainty for eight nominal and real economic indicators. Second, we measure the country-specific uncertainty as the weighted average of standardized components of variable-specific uncertainty measures. Finally, we propose an index of global uncertainty, which is a rather new concept in the literature. ${ }^{1}$ Constructed from a large set of countries, corresponding to more

\footnotetext{
${ }^{1}$ Our data are available at monthly frequencies on http://www.american.edu/cas/faculty/sheng.cfm
} 
than 90 percent of the world economy, this global measure is more comprehensive than the previously proposed measures, e.g. Berger and Herz (2014).

Our main findings are summarized as follows. All uncertainty measures are countercyclical and at all layers, combined uncertainty is more countercyclical than its common or idiosyncratic component. A comparison of our country-specific uncertainty measures with alternative leading measures from the literature for a subset of countries shows that our measures have fewer peaks, all around the recessions, and have persistent and heightened uncertainty during the recession episodes. Shocks to our measures of uncertainty are associated with large and persistent drops in real activity at both national and global levels. Further investigation shows that common uncertainty shocks produce large and persistent responses in real activity, whereas the contributions of idiosyncratic uncertainty shocks are negligible.

The rest of the paper is organized as follows. Section 2 details the methodology on measuring uncertainty. Section 3 introduces the data used in this paper. Section 4 describes the properties of economic uncertainty measures. Section 5 presents the dynamic relationship between uncertainty and economic activity and Section 6 concludes. The online appendix includes detailed information on the dataset, alternative measures of country-specific uncertainty using principal component analysis and regional measures of uncertainty.

\section{Methodology: Estimating Uncertainty}

\subsection{Uncertainty Decomposition}

Our decomposition of the uncertainty of a typical forecaster is motivated by the literature on the capital asset pricing model (CAPM) that decomposes the return volatility of a typical stock into market volatility and firm-specific volatility. We start off by presenting the traditional CAPM decomposition that requires estimation of firm-specific betas and then move 
to the approach in Campbell et al. (2001) that does not require any information about individual betas on the aggregate level.

Let $e_{i t}$ be individual $i$ 's forecast error at time $t$. Then, consensus forecast error, $e_{t}$, is defined as the weighted average of individual forecast errors:

$$
e_{t}=\sum_{i=1}^{N} w_{i t} e_{i t}
$$

where $w_{i t}$ is the weight of individual forecast error in consensus forecast error. Parallel to the CAPM literature that connects firm-specific return to market return, we specify the relationship between individual and consensus forecast errors as follows

$$
e_{i t}=\beta_{i} e_{t}+\varepsilon_{i t}
$$

where $\beta_{i}$ measures individual $i$ 's tendency to respond to common shocks, as proxied by consensus forecast error $e_{t}$. Beta is important since it captures the risk arising from exposure to general economic conditions as opposed to idiosyncratic factors. The $\beta_{i}$ below 1 indicates that an individual forecast error is not highly correlated with consensus forecast error. In equation (2), $\varepsilon_{i t}$ is orthogonal by construction to $e_{t}$. Equations (1) and (2) together impose the following restriction $\sum_{i=1}^{N} w_{i t} \beta_{i}=1$, which is the standard assumption in the CAPM literature that the weighted sums of the different betas equal unity. Equation (2) permits a simple variance decomposition in which the covariance term is zero:

$$
\operatorname{Var}\left(e_{i t}\right)=\beta_{i}^{2} \operatorname{Var}\left(e_{t}\right)+\operatorname{Var}\left(\varepsilon_{i t}\right)
$$

In equation (3), $\operatorname{Var}\left(e_{t}\right)$ measures the common volatility and $\operatorname{Var}\left(\varepsilon_{i t}\right)$ captures the idiosyncratic volatility. The problem with this decomposition, however, is that it requires knowledge of individual-specific betas that are difficult to estimate and introduce another layer of uncertainty in parameter estimation. To avoid this problem, we follow the approach in 
Campbell et al. (2001) that does not require any information about individual betas on the aggregate level. To fix ideas, let $u_{i t}$ denote the difference between $e_{i t}$ and $e_{t}$ :

$$
e_{i t}=e_{t}+u_{i t}
$$

Plugging equation (4) into equation (2) and re-arranging yields

$$
u_{i t}=\left(\beta_{i}-1\right) e_{t}+\varepsilon_{i t}
$$

The apparent drawback of equation (4) is that $u_{i t}$ and $e_{t}$ are not orthogonal, and so we cannot ignore their covariance. Taking the variance on both sides of equation (4), we have

$$
\begin{array}{r}
\operatorname{Var}\left(e_{i t}\right)=\operatorname{Var}\left(e_{t}\right)+\operatorname{Var}\left(u_{i t}\right)+2 \operatorname{Cov}\left(e_{t}, u_{i t}\right) \\
=\operatorname{Var}\left(e_{t}\right)+\operatorname{Var}\left(u_{i t}\right)+2\left(\beta_{i}-1\right) \operatorname{Var}\left(e_{t}\right),
\end{array}
$$

where the second equality follows from equation (5). Again, taking into account the covariance term introduces the individual forecaster beta into the variance decomposition.

Note, however, that although the variance of an individual forecast error contains the covariance term, the weighted average of variances across forecasters is free of the covariance term and individual betas:

$$
\sum_{i=1}^{N} w_{i t} \operatorname{Var}\left(e_{i t}\right)=\operatorname{Var}\left(e_{t}\right)+\sum_{i=1}^{N} w_{i t} \operatorname{Var}\left(u_{i t}\right)
$$

The covariance term from equation (6) aggregates out due to the standard restriction $\sum_{i=1}^{N} w_{i t} \beta_{i}=1$. The weighted average $\sum_{i=1}^{N} w_{i t} \operatorname{Var}\left(e_{i t}\right)$ can be interpreted as the volatility of a "typical" forecaster, selected randomly from among all forecasters with probability equal to its weight $w_{i t}$, e.g. Giordani and Söderlind (2003). Equation (7) states that the volatility of a typical forecaster can be decomposed into two parts: volatility that is common to all forecasters and volatility that arises from the heterogeneity of individual forecasters.

The observed disagreement among forecasts (or forecast errors) can be expressed as

$$
d_{t}=\sum_{i=1}^{N} w_{i t}\left(e_{i t}-e_{t}\right)^{2}
$$




$$
\begin{aligned}
& =\sum_{i=1}^{N} w_{i t}\left[\left(\beta_{i}-1\right) e_{t}+\varepsilon_{i t}\right]^{2} \\
& =\sum_{i=1}^{N} w_{i t}\left[\left(\beta_{i}-1\right)^{2} e_{t}{ }^{2}+\varepsilon_{i t}{ }^{2}+2\left(\beta_{i}-1\right) e_{t} \varepsilon_{i t}\right] .
\end{aligned}
$$

The sample variance $d_{t}$ is a random variable prior to observing the forecasts. Taking expectations, we get an expression for the non-random disagreement, denoted by $D_{t}$, as

$$
\begin{aligned}
D_{t} \equiv E\left(d_{t}\right)= & \sum_{i=1}^{N} w_{i t}\left[\left(\beta_{i}-1\right)^{2} E\left(e_{t}{ }^{2}\right)+E\left(\varepsilon_{i t}{ }^{2}\right)+2\left(\beta_{i}-1\right) E\left(e_{t} \varepsilon_{i t}\right)\right] \\
& =\sum_{i=1}^{N} w_{i t}\left[\left(\beta_{i}-1\right)^{2} \operatorname{Var}\left(e_{t}\right)+\operatorname{Var}\left(\varepsilon_{i t}\right)\right]
\end{aligned}
$$

where the last equality holds since $E\left(e_{t} \varepsilon_{i t}\right)=0$ and $E\left(e_{t}\right)=0$ by assumption. Taking the variance on both sides of equation (5), we have

$$
\operatorname{Var}\left(u_{i t}\right)=\left(\beta_{i}-1\right)^{2} \operatorname{Var}\left(e_{t}\right)+\operatorname{Var}\left(\varepsilon_{i t}\right) .
$$

Plugging equation (10) into equation (9) yields

$$
D_{t}=\sum_{i=1}^{N} w_{i t} \operatorname{Var}\left(u_{i t}\right) \text {. }
$$

Combining equation (11) with equation (7), we get

$$
\sum_{i=1}^{N} w_{i t} \operatorname{Var}\left(e_{i t}\right)=\operatorname{Var}\left(e_{t}\right)+D_{t} .
$$

Equation (12) decomposes the uncertainty of a typical forecaster into common and idiosyncratic uncertainty. The first component is the empirical variance of the consensus forecast, which is conventionally the common uncertainty in the literature; see Clements (2014). The second component is the forecast disagreement and captures idiosyncratic uncertainty $^{2}$ Finally, we need to point out that our uncertainty decomposition is similar to the decomposition as in Lahiri and Sheng (2010) under a panel data framework.

\footnotetext{
${ }^{2}$ It is easy to show how our measure of idiosyncratic uncertainty, $\sum_{i=1}^{N} w_{i t} \operatorname{Var}\left(u_{i t}\right)$, relates to the "true" measure, $\sum_{i=1}^{N} w_{i t} \operatorname{Var}\left(\varepsilon_{i t}\right)$. To this end, we take the weighted average of equation (10): $\sum_{i=1}^{N} w_{i t} \operatorname{Var}\left(u_{i t}\right)=$ $\sum_{i=1}^{N} w_{i t}\left(\beta_{i}-1\right)^{2} \operatorname{Var}\left(e_{t}\right)+\sum_{i=1}^{N} w_{i t} \operatorname{Var}\left(\varepsilon_{i t}\right)$. The wedge between the two idiosyncratic uncertainty measures is determined by the cross-sectional variance of $\beta_{i}$ across all individual forecast errors, $\sum_{i=1}^{N} w_{i t}\left(\beta_{i}-1\right)^{2}$ and common uncertainty, $\operatorname{Var}\left(e_{t}\right)$. Lahiri and Sheng (2008) show that the cross-sectional variance of $\beta_{i}$ across all individual forecast errors is sufficiently small. Thus, our measure of idiosyncratic uncertainty can be a reasonable proxy for the "true" measure of idiosyncratic uncertainty.
} 


\subsection{Estimation}

Based on the uncertainty decomposition in equation (12), we construct time series of the two components of uncertainty measure for each variable, each country, and finally for the world. In this subsection, we discuss how we estimate common and idiosyncratic components of variable-specific, country-specific, and global uncertainty measures.

The common uncertainty shocks have long been estimated using GARCH-type models, dating back to Engle (1982). Under such a framework, the estimates of common uncertainty depend on innovations to the raw series, denoted by $Y_{t}$, and therefore cannot be separated from first-moment shocks. For this reason, we use the stochastic volatility model to estimate common uncertainty in our main analysis. ${ }^{3}$ The stochastic volatility model permits construction of a shock to the second moment that is independent of innovations to $Y_{t}$. This exogeneity is consistent with the theoretical literature which presumes the existence of an uncertainty shock that independently affects real activity. Estimation of the common uncertainty using a stochastic volatility model has the following specification:

$$
\begin{aligned}
& e_{t}=\varphi_{0}+\varphi_{1} \varepsilon_{t-1}+\varepsilon_{t}, \varepsilon_{t} \mid I_{t-1} \sim N\left(0, \sigma_{t}^{2}\right) \\
& \ln \sigma_{t}^{2}=\alpha+\beta \ln \sigma_{t-1}^{2}+v_{t} .
\end{aligned}
$$

We estimate this model using Markov Chain Monte Carlo (MCMC) methods as in Kim et al. (1998). To prevent the impacts of the outliers, we use median forecast errors instead of mean forecast errors to estimate common uncertainty, $\sigma_{t}^{2}$.

We measure forecast disagreement, $D_{t}$ in equation (12), as the interquartile range of forecasts of survey respondents rather than their standard deviation in order to mitigate the effect of the outliers, as is common in the literature; e.g. Mankiw, et al. (2003) and Dovern,

\footnotetext{
${ }^{3}$ For a robustness check, we also use the GARCH model to estimate common uncertainty. We find that the resulting uncertainty estimates from stochastic volatility model and GARCH model are very similar.
} 
et al. (2012). With both common uncertainty $\sigma_{c j t}^{2}$ and idiosyncratic uncertainty $D_{c j t}$ at hand, our variable-specific uncertainty $U_{c j t}$ for country $c$, variable $j$ at time $t$ can be estimated as

$$
U_{c j t}=\sigma_{c j t}^{2}+D_{c j t}
$$

Since these two components of uncertainty measure have different scales, we standardize them using the min-max normalization rule. Applying this rule, both common and idiosyncratic uncertainty components are scaled between 0 and 1 , and the sum of these two is bounded between 0 and 2 for all eight variables including GDP, consumption, investment, industrial production, inflation, unemployment rate, short-term and long-term interest rates. Variablespecific uncertainty estimates have two prominent features. ${ }^{4}$ First, guided by the recent empirical findings that surveys provide more accurate forecasts than models (see, for example, Ang et al. (2007) and Faust and Wright (2013)), we use surveys of professional forecasters directly rather than making objective statistical forecasts. Thus, our uncertainty estimates are less prone to measurement errors due to potentially misspecified econometric models that yield large forecast errors and inflated uncertainty estimates. Second, we use forecast errors, rather than forecasts, to remove the predictable component of the raw series and estimate common uncertainty as the conditional volatility of the purely unforecastable component of the future value of the series.

To estimate country-specific economic uncertainty, we take the weighted average of eight variable-specific uncertainty estimates as follows:

$$
U_{c t}=\sum_{j=1}^{J} w_{j} U_{c j t}
$$

\footnotetext{
${ }^{4}$ The min-max rescaling does not affect the patterns of the common or idiosyncratic uncertainty. Idiosyncratic uncertainty is measured as the interquartile range of the forecasts of survey respondents, whereas common uncertainty is estimated as the conditional volatility of mean/median forecast errors. As the patterns of both uncertainty measures remain the same, the relative importance of the two kinds of shocks just becomes comparable after the min-max rescaling.
} 
We present the results using equal weights $w_{j}=\frac{1}{J}$ in the paper. As an alternative, we also estimate the country-specific uncertainty as the first principal component of eight variablespecific uncertainty series and find that the results are very similar. ${ }^{5}$ This definition emphasizes that economic uncertainty is a measure of common variation in uncertainty across many series, as also pointed out by Jurado, et al. (2015).

Unlike the variable-specific and country-specific uncertainty measures, global uncertainty receives little attention in the literature. This is possibly due to insufficient data to estimate global uncertainty. The existing global uncertainty measures are based on too few countries and tend to focus on developed economies. For instance, Hirata et al. (2013) construct a measure of global uncertainty based on stock price volatility in seven advanced economies and Berger and Herz (2014) estimate global uncertainty using nine advanced economies and two variables. To address these limitations, we use a dataset of 45 advanced and emerging market economies, covering more than 90 percent of the world economy today. For these economies, we include eight variables for each country, covering both real and nominal variables. Taking advantage of this rich dataset, we construct a measure of global uncertainty as the purchasing power parity (PPP)-weighted average of the country-specific uncertainties. ${ }^{6}$

\section{Data}

We use survey data of macroeconomic forecasts to compute uncertainty measures. The forecast data are from the Consensus Forecasts, publications of the Consensus Economics Inc., a private macroeconomic survey firm based in London. This survey is a comprehensive dataset

\footnotetext{
${ }^{5}$ Figure A1 in the online appendix presents the country-specific uncertainty measures of the G7 countries estimated as the first principal component of eight variable-specific uncertainty measures.

${ }^{6}$ Instead of PPP weights, using market GDP weights provides very similar results.
} 
with a large coverage of advanced and emerging market economies. For each country, the survey asks similar questions to a panel of 10-30 professional forecasters, all based in the home country, on the first week of each month. For some countries, the definition of variables varies slightly (i.e. manufacturing production instead of industrial production) and for others some questions are omitted because of possible data limitations. Other than these, the surveys have a near uniform design for all countries in the sample, which makes the results comparable across countries. Our study covers all 45 countries with monthly forecasts available for the annual growth rates of GDP, consumption, investment, industrial production, and levels of inflation, short-term and long-term interest rates, and the unemployment rate. These eight variables enable us to capture uncertainty both in nominal and real macroeconomic series, where inflation, short-term and long-term interest rates are in nominal and the rest are in real terms. Table A.1 in the online appendix provides detailed information on the country, time and variable coverage of the dataset.

Forecasts for all variables except interest rates are fixed event forecasts. Every month, each survey participant provides forecasts for both the current and next calendar year. These fixed event forecasts get closer to the actual values when the forecasting horizon is shorter. Following Dovern, et al. (2012), we transform the fixed event forecasts of all variables into fixed horizon forecasts with the following adjustment:

$$
F_{i, t+12 \mid t}=\frac{k}{12} F_{i, t+k \mid t}+\frac{12-k}{12} F_{i, t+12+k \mid t},
$$

where $F_{i, t+k \mid t}$ and $F_{i, t+12+k \mid t}$ are the two forecasts based on the information set at time $t$ with horizons of $k \in\{1, \ldots, 12\}$ and $k+12$ months, respectively. The average of two fixed event forecasts weighted by their share in the forecasting horizon approximates the fixed horizon forecast, $F_{i, t+12 \mid t}$, for the next 12 months. For interest rates, survey participants provide both 
three-month and twelve-month ahead forecasts. To be consistent with the horizon of the forecasts for other variables, we use the twelve-month ahead forecasts for both short-term and long-term interest rates.

Turning to the actual values, monthly series are available for industrial production, inflation, unemployment, short-term and long-term interest rates. For real GDP, consumption and investment, we use quarterly series as they are not available at the monthly frequency and we use the value belonging to a quarter for each of the three months in that quarter. The main sources of actual values are Global Data Source of IMF, Haver Analytics, OECD Analytical databases and country statistical offices. To match the actual values with the fixed-horizon forecasts, we perform the appropriate data transformation. ${ }^{7}$ We explore the properties of these forecasts through the Mincer-Zarnowitz regression and find that some forecasts are biased and inefficient in incorporating new information. ${ }^{8}$ Despite these inefficiencies, we use forecast data because of the advantages of surveys over purely model-based forecasts and because these surveys reflect market participants' perceptions of economic development in the future. These perceptions are the key to capturing how economic agents experience uncertainty in the economy.

\footnotetext{
${ }^{7}$ Take as an example the survey conducted in January 1991. At the beginning of January, the survey asks forecasts for industrial production and inflation for 1991. For these two monthly variables, we calculate the actual values as the growth rate between December 1990 and December 1991. Similarly, for real GDP, consumption and investment, we calculate the respective actual values as the growth rate between the fourth quarter of 1990 to the fourth quarter of 1991. For the unemployment rate, the actual value reflects the rolling 12-month window average, and in this example, equals the average of the unemployment rates from January to December 1991. The forecasts of the two interest rates in this study are easily comparable to the actual values. For both the short- and long-term interest rates, the actual values are the monthly data released for the target date.

${ }^{8}$ Since the forecasters in the survey are not anonymous, the possibility exists that at least part of the bias and inefficiency can be explained by strategic behavior among them. On one hand, forecasters might shade their forecasts toward the consensus to avoid unfavorable publicity when wrong. On the other hand, forecasters might deviate from the consensus to stand out from the crowd of competing forecasters. While there is supporting evidence for both types of strategic behavior, their overall effects on forecast accuracy and the resulting uncertainty estimates are not clear. Conducting the detailed analysis of forecasters' objectives and strategies is beyond the scope of this paper and we leave it for future research.
} 


\section{Properties of Economic Uncertainty}

We estimate variable-specific uncertainty (VSU) for eight indicators. For most of the economies in the sample, the VSU is countercyclical for all series. Moreover, some VSU estimates are highly correlated. Table 1 shows that, for the United States, the pairwise correlations are quite high for most of the VSU estimates. Interestingly, pairwise correlations between all VSU estimates except long-term interest rate are higher for the common than for the idiosyncratic component. For instance, the correlation between inflation and investment growth is 0.27 for idiosyncratic uncertainty, but 0.78 for common uncertainty. If one estimates uncertainty at the country level using only forecast disagreement, then there would be too many uncertainty spikes due to idiosyncratic shocks in individual series. On the other hand, if one estimates uncertainty using only the common component, then the series would be too smooth. These findings imply that the combined estimate of these two reflects the uncertainty in the entire economy better than any individual component.

For all countries, common uncertainty is less volatile and on average, higher than idiosyncratic uncertainty. There are very few peaks in common uncertainty and those peaks are usually around recessions. For instance, in the United States, the uncertainty for output, consumption, investment, unemployment rate and short-term interest rates increases during all three recession periods covered in the sample of $1989-2014 .{ }^{9},{ }^{10}$ Interestingly, some regional recession episodes are associated with higher uncertainty than global recession episodes. For instance, in Indonesia and South Korea, some of the VSU peaks around the 1997 Asian

\footnotetext{
${ }^{9}$ Recession dates are taken from Claessens et. al (2016) that identifies the turning points using a non-parametric approach for 75 advanced and emerging market economies. Alternatively, turning points from Economic Cycle Research Institute can be used, but this source covers only 22 out of 45 countries in our sample.

${ }^{10}$ The uncertainty measures introduced in this paper will be revised and published here every other year.
} 
financial crisis are higher than those around the recent global recession. This is consistent with the findings of Hirata, et al. (2013): since the mid-1980s the importance of regional factors has increased and global factors play a lesser role in explaining international business cycles.

Turning to the country-specific uncertainty (CSU), Figure 1 plots the uncertainty estimates for 45 advanced and emerging market economies. The CSU is strongly countercyclical. Almost in all countries, the CSU peaked around 2009, even though the country itself did not experience any recession, e.g. China and Australia. For some emerging market economies, the uncertainty was higher during earlier recessions than the latest global recession. For instance, the largest uncertainty peak for Argentina is around 2001-2002 when there was a deep financial crisis in the country, whereas for Hong Kong it is around 1997-1998 Asian financial crisis.

The uncertainty at the national level influences the variable-specific uncertainty. To explore this impact, Table 2 presents the proportion of variable-specific uncertainty that is explained by the country-specific counterpart. For the entire sample, on average, the explanatory power of the CSU for the variable-specific uncertainty is almost the same during recessions $\left(R^{2}=0.585\right)$ and expansions $\left(R^{2}=0.576\right)$. For the advanced economies, however, it is higher during recessions $\left(R^{2}=0.51\right)$ than expansions $\left(R^{2}=0.46\right)$. Shorter time coverage of the emerging market economies makes it difficult to compare the explanatory power at different phases of the business cycle. For eight out of fifteen advanced economies, the CSU explains output growth uncertainty the most. Furthermore, the explanatory power varies over business cycles. For instance, in the United Kingdom, the CSU explains investment growth uncertainty the best during recessions but the least during expansions. In Japan, the variable that the CSU explains the most is inflation uncertainty during recessions but output 
growth uncertainty during expansions. For emerging market economies, the evidence is rather mixed. For instance, $R^{2}$ is highest for industrial production uncertainty in China, Poland, and Czech Republic; for consumption uncertainty in Argentina, Brazil, Colombia, Peru, South Korea, Philippines, Lithuania, and Romania; for investment uncertainty in Bulgaria, Croatia and Russia. Taken together, we see that country-specific uncertainty accounts for a large fraction of the variation in the variable-specific uncertainty. But there is a large amount of idiosyncratic variation in uncertainty across variables, as evident from many $R^{2}$ statistics that are much lower than one.

Our country-specific uncertainty measure complements the uncertainty estimate proposed by Jurado, et al. (2015) in two dimensions. First, we use surveys of professional forecasters available for many countries and focus on market participants' perceived uncertainty; whereas they generate forecasts from augmented autoregressive models and measure uncertainty only for the U.S. around objective statistical forecasts. Second, they measure macroeconomic uncertainty as the common factor of all uncertainty estimates of hundreds of variables. In contrast, our uncertainty measure captures both common and idiosyncratic uncertainties that have different effects on economic activity as we show in the next section.

With national uncertainty at hand, we estimate global uncertainty as the weighted average of country-specific uncertainties in Figure 2. Global uncertainty is strongly countercyclical and rises during the global recessions of 1991 and 2009, identified by Kose and Terrones (2015). The country-specific uncertainty is potentially influenced by global uncertainty because of large trade and financial interconnectedness among economies. Table 3 shows the proportion of the variation in the country-specific uncertainty that is explained by 
global uncertainty. In some of the Asian economies, global uncertainty explains only a small fraction of the country-specific uncertainty. For instance, $R^{2}$ is 0.435 in Hong Kong and 0.079 in Thailand. On the other hand, in some of the Eastern European economies, global uncertainty explains a very large fraction of the country-specific uncertainty, e.g. $R^{2}=0.925$ in Lithuania, 0.904 in Latvia and 0.886 in Bulgaria. In addition, global uncertainty amplifies the countryspecific uncertainty for almost half of the sample, where the coefficient is significantly larger than 1. This amplification is less evident for its common component than idiosyncratic component. ${ }^{11}$ Finally, global uncertainty has the largest explanatory power relative to its two components. Parallel to other layers of uncertainty, the sum of both components better reflects worldwide uncertainty than any individual component. ${ }^{12}$

Table 4 presents the correlations among uncertainty, its two components, and other uncertainty measures for the United States. Our uncertainty measure has the highest correlation (0.79) with the uncertainty measure proposed by Jurado et al. (2015) and the lowest correlation (0.18) with the economic policy uncertainty measure proposed by Baker, et al. (2016) ${ }^{13}$ Not surprisingly, the measure of Jurado et al. (2015) has a higher correlation with common uncertainty (0.75) than idiosyncratic uncertainty (0.59). The lower correlation with idiosyncratic uncertainty reflects that disagreement captures other information, such as

\footnotetext{
${ }^{11}$ Common uncertainty always refers to the "conditional volatility of the purely unforecastable component of the future value of the series". In the global context, common uncertainty is the weighted averages of the part that is not covered by the forecast disagreement of national forecasters for the national economies, with weights determined by the share of each national economy in the global economy. Common uncertainty should not be confused with the uncertainty "that is similarly faced by all countries or groups of countries". Instead, it is a weighted average of "common national uncertainty" measures.

${ }^{12}$ Parallel to the global uncertainty measure, Figure A2 in the online appendix presents the uncertainty of functional and regional country groups, categorized as in the Consensus Forecasts dataset.

${ }^{13}$ Our uncertainty measure for the U.S. is weakly correlated (0.38) with the uncertainty index in Scotti (2016). Table 4 covers the November 1989 - July 2014 period for all uncertainty measures except Scotti (2016), which starts from May 2003.
} 
heterogeneous models and differential interpretation of public information, which are ignored by common uncertainty.

Figure 3 compares our country-specific uncertainty with other uncertainty measures from the literature, where all measures are standardized to have zero mean and unit variance for easy comparison. For almost all twelve countries included in this comparison, the increases in our uncertainty measures are more persistent during recessions compared to alternative uncertainty measures. For the United States, all uncertainty measures are countercyclical. Only our measure and the policy uncertainty measure exceed the 1.65 standard deviation line for all three recession periods. However, the policy uncertainty exceeds this line many more times after the end of the latest recession. On the other hand, the uncertainty measure of Jurado et al. (2015) exceeds the line only once during the latest recession, and the VXO exceeds the line six times, covering the three recessions and three non-recession periods. For the United Kingdom, the policy uncertainty exceeds the 1.65 standard deviation line five times, whereas our measure exceeds the line in two recessions out of three. For Canada, France and Germany, our measure usually performs better than the policy uncertainty in capturing the recessionary episodes. For Japan, the uncertainty index of Scotti (2016) does not exceed the 1.65 standard deviation line anytime around or during the 2007-09 recession, whereas our uncertainty measure does. For the other countries, the comparison is between our measure and the newsbased uncertainty index of Baker et al. (2016). Based on the uncertainty-related keyword search on main newspapers, the news-based indexes often experience large spikes during nonrecessionary episodes. On the other hand, our uncertainty measures for these countries reach their peaks during most of the recessionary episodes and remain low during expansions. 


\section{Uncertainty and Economic Activity}

In this section, we analyze economic uncertainty and macroeconomic dynamics. One of the most pronounced reasons for the slow recovery has been the elevated macroeconomic uncertainty during and after the global recession. To explain this slow recovery, some studies emphasize the demand side impacts of uncertainty via consumption and investment. With high uncertainty, households save more and postpone their consumption, especially for durable goods. Similarly, companies delay their investment decisions and choose to "wait and see" until high uncertainty is resolved (Bloom, 2009). Other studies investigated the supply side impacts of uncertainty through credit provision and productivity growth. When economic uncertainty is high, banks are reluctant to provide loans, and credit conditions for companies tighten, especially for new start-up companies which are good sources of innovation and high productivity growth, e.g. Gilchrist, et al. (2014). ${ }^{14}$

The dynamics between uncertainty and economic activity has been analyzed using vector autoregression (VAR) models. To easily benchmark with the results in the literature, we employ the VAR analysis as well. We use an eight-variable model and present the results for the United States only. Our VAR model has the following specification: $\log (\mathrm{S} \& \mathrm{P} 500$ index), uncertainty measure, Federal funds rate, $\log$ (wages), $\log$ (consumer price index), hours, $\log ($ employment), $\log ($ industrial production). Figure 4 plots the responses of industrial production and employment to a one standard deviation uncertainty shock. ${ }^{15}$ There is clear

\footnotetext{
${ }^{14}$ The idiosyncratic component of macroeconomic uncertainty could be addressed by some policies. For instance, with better communication, central banks could affect the forecasts of private sectors on inflation and lower the disagreement among them. In contrast, it is difficult for policies to affect the conditional volatility of the purely unforecastable component of the future value of the series.

${ }^{15}$ As an alternative, we estimate the VAR model by ordering the uncertainty the last and find that the results are very similar.
} 
evidence of overshooting when the VXO or economic policy uncertainty is used as the proxy. In the middle of the third year after the hit of the VXO shock, both industrial production and employment increase over their initial levels. The overshooting is even faster when economic policy uncertainty is used as a proxy, in line with Bloom (2009). Both employment and industrial production decline sharply in response to a one standard deviation shock to the uncertainty measure of Jurado et al. (2015) and these declines remain persistent for five years following the initial shock.

We also analyze the impact of the two components of country-specific uncertainty through the VAR model. The idiosyncratic component, forecast disagreement shock, has less significant impacts on industrial production and employment. In contrast, common uncertainty shocks have a large and long-lived impact on both industrial production and employment, with the peak impact occurring after two to three years. Therefore, the "wait-and-see" mechanism is observed in the common component of the uncertainty rather than its idiosyncratic component. Turning to our country-specific uncertainty measure that includes both common and idiosyncratic components, the responses of both industrial production and employment are not significant during the first nine months following the shock. The significantly negative impact on industrial production starts around 10 months after the shock and remains persistent, keeping industrial production below its initial level until the middle of the third year. This finding underscores the larger persistence of our country-specific uncertainty measure as compared to most other uncertainty proxies, such as VXO and EPU. ${ }^{16}$

\footnotetext{
${ }^{16}$ Another possible explanation for the delayed response is that the most significant response to the recession shock was delayed in the actual data as well. For example, in the United States, the largest consecutive monthover-month decline in employment was 5 to 14 months after the beginning of the three latest recessions, and for the industrial production the largest month-over-month decline was 5 to 10 months after the start of these recessions. Moreover, these largest declines are 3 to 20 times larger than the declines in earlier months. This might explain the delayed responses to our uncertainty shocks, which peaks the most around the recession episodes. Of course, there might be other reasons for the delayed response and we leave it for future research.
} 
Using global uncertainty measure and monthly variables, we conduct a similar exercise in the global dimension. Our VAR model includes seven variables in the following order: stock prices, global uncertainty, short term interest rate, oil prices, food prices, unemployment rate and industrial production. ${ }^{17}$ Besides global uncertainty, we also use its common and idiosyncratic components, replacing the uncertainty measure iteratively in the model. Figure 5 shows the impulse response functions. For industrial production (panel A), there is an immediate decline following the global uncertainty shock, but the decrease dissipates within a few months. The response to the idiosyncratic uncertainty shock has a similarly short-lived impact, but an overshooting occurs after six months following the initial shock. The response to the common uncertainty shock, on the other hand, has a long-lived impact on industrial production, with the peak impact occurring after two years. The differences in the impact of the common and idiosyncratic uncertainty shocks show how these two parts capture different features of global uncertainty.

As illustrated in panel B of Figure 5, the global uncertainty shocks lead to a sizable and protracted increase in unemployment, a phenomenon that was observed during and after some recessions, notably the recent global recession and its aftermath. The significant increase in unemployment following the uncertainty shock dissipates almost after 30 months. The idiosyncratic uncertainty shocks are associated with high initial response in unemployment rate, which then overshoots after 30 months. The common uncertainty shocks lead to more persistent and high unemployment rates and the impacts peak around 30 months. These

\footnotetext{
${ }^{17}$ Actual monthly values of the series are as follows. Stock prices are the monthly world stock market index from Global Data Source (GDS) of the IMF, Global short-term interest rate is the 1-month London Inter Bank Offer Rate (LIBOR) from IFS. Oil prices are the monthly average crude oil price per barrel from IFS. Global food prices are monthly average food prices from IFS. Monthly world unemployment rate and industrial production are from GDS.
} 
findings support the theory that employers "wait-and-see" before they decide to lay off after the initial shock and then hire later during the recovery.

Due to the imperfect correlation between common and idiosyncratic uncertainty, we perform an additional analysis by jointly studying their roles in explaining business cycle fluctuations. To this end, we include both uncertainty measures in the VAR model specification as follows: $\log ($ stock price), common uncertainty, idiosyncratic uncertainty, monetary policy rate, $\log ($ consumer price index $), \log$ (industrial production). ${ }^{18}$ As shown in Figure 6, the two components of uncertainty have different effects on industrial production. Common uncertainty shocks have large and persistent impacts whereas idiosyncratic uncertainty shocks have short-lived and negligible effects on industrial production. This pattern holds for France, Italy, Japan, United Kingdom and United States. For Canada and Germany, however, both types of uncertainty shocks seem to have very limited and short-lived effects.

\section{Conclusion}

This paper makes two contributions to the growing literature on economic uncertainty. First, we decompose the uncertainty of a typical forecaster into common and idiosyncratic uncertainty and accordingly propose a new monthly index of uncertainty that has both components, namely, perceived variability of future aggregate shocks and the disagreement among forecasters. By including these two components, the uncertainty measure captures economic uncertainty along different dimensions. Second, we use actual forecasts of market analysts instead of using hindsight to specify econometric forecasts. This choice is especially

\footnotetext{
${ }^{18}$ Note that the variables used for Figure 6 are different from those used to produce Figure 4. For countries other than the United States, it is hard to find monthly wage, employment, and hours of work data. Therefore, the analysis used for Figure 6 omits these three variables for all countries.
} 
important since relevant information not used in model estimation and forecasting will lead to spurious estimates of uncertainty. As such, our uncertainty measure incorporates a rich information set and captures perceived uncertainty for market participants.

Compared to other leading measures, our country-specific uncertainty measures have fewer peaks, but when they do occur, they are larger and more persistent, a feature particularly relevant for theories where uncertainty is a driving force of recessions. Using the VAR analysis, we find that shocks to country-specific uncertainty are associated with a sizable and protracted decline in real activity. This result also holds for the world economy: global uncertainty shocks have long-lived effects on industrial production and unemployment. A deeper investigation shows that the two components of economic uncertainty exhibit strikingly different behavior. Common uncertainty shocks account for a large fraction of fluctuations in economic activity at business cycle frequencies, whereas idiosyncratic uncertainty shocks play a small role. Future research is warranted to quantify the economic effects of different types of uncertainty and analyze the transmission of uncertainty shocks across countries.

\section{Acknowledgements}

This paper was presented at the 2nd Society for Economic Measurement Conference, 8th International Conference on Computational and Financial Econometrics, 21st Federal Forecasters Conference, 24th Symposium of the Society for Nonlinear Dynamics and Econometrics, 35th International Symposium on Forecasting, London workshop on "Impact of Uncertainty Shocks on the Global Economy," Stanford workshop on "The Macroeconomics of Uncertainty and Volatility," Banque de France, George Washington University and Texas Tech University. We thank the conference and seminar participants for very helpful comments. 
We also thank the internal reviewers from various departments of the IMF for their useful comments. The views expressed in this paper are those of the authors and do not necessarily represent views and policies of the IMF. 


\section{References}

Ang, Andrew, Geert Bekaert, and Min Wei, 2007, "Do Macro Variables, Asset Markets, or Surveys Forecast Inflation Better?’ Journal of Monetary Economics, Vol. 54, pp. 1163 1212.

Bachmann, Rüdiger, Steffen Elstner, and Eric R. Sims, 2013, "Uncertainty and Econmic Activity: Evidence from Business Survey Data," American Economic Journal: Macroeconomics, Vol. 5, No. 2, pp. 217-49.

Baker, Scott R., Nicholas Bloom, and Steven J. Davis, 2016, "Measuring Economic Policy Uncertainty," Quarterly Journal of Economics, Vol. 131, No. 4, pp. 1593-1636.

Bekaert, Geert, Marie Hoerova and Marco Lo Duca, 2013, "Risk, Uncertainty and Monetary Policy," Journal of Monetary Economics, Vol. 60, pp. 771-788.

Berger, Tino and Sibylle Herz, 2014, "Global Macroeconomic Uncertainty” Working Paper, University of Muenster.

Bloom, Nicholas, 2009, “The Impact of Uncertainty Shocks," Econometrica, Vol. 77, No. 3, pp. 623-85.

Campbell, John, Martin Lettau, Burton Malkiel, and Yexiao Xu, 2001, "Have Individual Stocks Become More Volatile? An Empirical Exploration of Idiosyncratic Risk,” Journal of Finance, Vol. 56, No. 1, pp. 1-43.

Claessens, Stijn, Ayhan Kose, Ezgi O. Ozturk, and Marco Terrones, 2016, “A Global Database of Business and Financial Cycles," IMF working paper.

Clements, Michael P., 2014, "Forecast Uncertainty - Ex ante and Ex post: U.S. Inflation and Output Growth," Journal of Business and Economic Statistics, Vol. 32, pp. 206-216. 
Dovern, Jonas, Ulrich Fritsche, and Jiri Slacalek, 2012, "Disagreement among Forecasters in G7 Countries," Review of Economics and Statistics, Vol. 94, pp. 1081-96.

Engle, Robert, 1982, "Autoregressive Conditional Heteroskedasticity with Estimates of the Variance of United Kingdom Inflation,” Econometrica, Vol. 50, No. 4, pp. 987-1007.

Faust, Jon and Jonathan H. Wright, 2013, "Forecasting Inflation," in Handbook of Economic Forecasting, eds. by G. Elliott and A. Timmermann, Elsevier, Vol. 2, pp. 2-56.

Gilchrist, Simon, Jae W. Sim, and Egon Zakrajsek, 2014, "Uncertainty, Financial Frictions, and Investment Dynamics," Working Paper, Boston University.

Giordani, Paolo and Paul Söderlind, 2003, "Inflation Forecast Uncertainty," European Economic Review, Vol. 47, pp. 1037-1059.

Hirata, Hideaki, M. Ayhan Kose, Christopher Otrok, and Marco E. Terrones, 2013, "Global House Price Fluctuations: Synchronization and Determinants," NBER International Seminar on Macroeconomics, University of Chicago Press, Vol. 9, No. 1, pp. 119-66.

Jo, Soojin, and Rodrigo Sekkel, 2015, "Macroeconomic Uncertainty through the Lens of Professional Forecasters," Working Paper, Bank of Canada.

Jurado, Kyle, Sydney C. Ludvigson, and Serena Ng, 2015, "Measuring Uncertainty," American Economic Review, Vol. 105, No. 3, pp. 1177-216.

Kilian, Lutz, 1998, "Small-sample confidence intervals for impulse response functions," Review of Economics and Statistics, No. 80.2, pp. 218-230.

Kim, Sangjoon, Neil Shephard, and Siddhartha Chib, 1998, "Stochastic Volatility: Likelihood Inference and Comparison with ARCH Models," Review of Economic Studies, Vol. 65, No. 3, pp. 361-393. 
Kose, M. Ayhan and Marco E. Terrones, 2015, Collapse and Revival: Understanding Global Recessions and Recoveries, International Monetary Fund.

Lahiri, Kajal and Xuguang Sheng, 2008, "Evolution of Forecast Disagreement in a Bayesian Learning Model," Journal of Econometrics, Vol. 144, pp. 325-340.

Lahiri, Kajal and Xuguang Sheng, 2010, "Measuring Forecast Uncertainty by Disagreement: the Missing Link," Journal of Applied Econometrics, Vol. 25, pp. 514-38.

Mankiw, N. Gregory, Ricardo Reis, and Justin Wolfers, 2003, "Disagreement on Inflation Expectations," NBER Macroeconomics Annual, pp. 209-48.

Rossi, Barbara and Tatevik Sekhposyan, 2015, "Macroeconomic Uncertainty Indices Based on Nowcast and Forecast Error Distributions," American Economic Review, Vol. 105, No. 5, pp. 650-55.

Scotti, Chiara, 2016, "Surprise and Uncertainty Indexes: Real-Time Aggregation of RealActivity Macro Surprises,” Journal of Monetary Economics, Vol. 82, pp. 1-19.

Stock, James and Mark Watson, 2012, "Disentangling the Channels of the 2007-09 Recession,” Brookings Papers on Economic Activity, Spring 2012, pp. 81-135. 
Table 1. Correlation between Variable-specific Uncertainty Measures:United States

A. Correlation between Variable-specific Uncertainty Meas ures

\begin{tabular}{|c|c|c|c|c|c|c|c|c|}
\hline & Output & Inflation & Consumption & Inves tment & $\begin{array}{c}\text { Indus trial } \\
\text { production }\end{array}$ & $\begin{array}{c}\text { Unemployment } \\
\text { rate } \\
\end{array}$ & $\begin{array}{c}\text { Short-term } \\
\text { interest rate }\end{array}$ & $\begin{array}{c}\text { Long-term } \\
\text { interest rate }\end{array}$ \\
\hline Output & 1.00 & & & & & & & \\
\hline Inflation & 0.57 & 1.00 & & & & & & \\
\hline Cons umption & 0.79 & 0.51 & 1.00 & & & & & \\
\hline Inves tment & 0.77 & 0.64 & 0.61 & 1.00 & & & & \\
\hline Industrial production & 0.82 & 0.70 & 0.61 & 0.79 & 1.00 & & & \\
\hline Unemployme nt rate & 0.77 & 0.53 & 0.72 & 0.70 & 0.67 & 1.00 & & \\
\hline Short-term interest rate & 0.43 & 0.22 & 0.55 & 0.42 & 0.37 & 0.28 & 1.00 & \\
\hline Long-term interest rate & 0.41 & 0.27 & 0.27 & 0.42 & 0.33 & 0.47 & 0.24 & 1.00 \\
\hline \multicolumn{9}{|c|}{ B. Corre lation betwe en Variable-s pecific Idios yncratic Unce rtainty Me as ures } \\
\hline & Output & Inflation & Consumption & Investment & $\begin{array}{c}\text { Indus trial } \\
\text { production }\end{array}$ & $\begin{array}{l}\text { Unemployment } \\
\text { rate }\end{array}$ & $\begin{array}{c}\text { Short-term } \\
\text { interest rate }\end{array}$ & $\begin{array}{c}\text { Long-term } \\
\text { interest rate }\end{array}$ \\
\hline Output & 1.00 & & & & & & & \\
\hline Inflation & 0.38 & 1.00 & & & & & & \\
\hline Consumption & 0.60 & 0.36 & 1.00 & & & & & \\
\hline Investment & 0.54 & 0.27 & 0.53 & 1.00 & & & & \\
\hline Industrial production & 0.56 & 0.46 & 0.53 & 0.51 & 1.00 & & & \\
\hline Unemployment rate & 0.49 & 0.30 & 0.53 & 0.46 & 0.39 & 1.00 & & \\
\hline Short-term interest rate & 0.19 & 0.02 & 0.17 & 0.15 & 0.02 & 0.02 & 1.00 & \\
\hline Long-term interest rate & 0.35 & 0.36 & 0.33 & 0.28 & 0.29 & 0.17 & 0.31 & 1.00 \\
\hline \multicolumn{9}{|c|}{ C. Correlation between Variable-specific Common Uncertainty Measures } \\
\hline & Output & Inflation & Consumption & Investment & $\begin{array}{c}\text { Indus trial } \\
\text { production }\end{array}$ & $\begin{array}{l}\text { Unemployment } \\
\text { rate }\end{array}$ & $\begin{array}{c}\text { Short-term } \\
\text { interest rate }\end{array}$ & $\begin{array}{c}\text { Long-term } \\
\text { interest rate }\end{array}$ \\
\hline Output & 1.00 & & & & & & & \\
\hline Inflation & 0.53 & 1.00 & & & & & & \\
\hline Cons umption & 0.83 & 0.50 & 1.00 & & & & & \\
\hline Inves tment & 0.75 & 0.78 & 0.60 & 1.00 & & & & \\
\hline Industrial production & 0.87 & 0.68 & 0.62 & 0.83 & 1.00 & & & \\
\hline Unemployment rate & 0.71 & 0.54 & 0.68 & 0.68 & 0.69 & 1.00 & & \\
\hline Short-term interest rate & 0.54 & 0.30 & 0.61 & 0.53 & 0.44 & 0.42 & 1.00 & \\
\hline Long-term interest rate & 0.20 & 0.20 & 0.16 & 0.22 & 0.19 & 0.49 & 0.17 & 1.00 \\
\hline
\end{tabular}

Note: Output, consumption, investment, and industrial production stand for the growth rates of these indicators. The sample is between $1989 \mathrm{M} 11-2014 \mathrm{M} 7$ for all estimates. 
Table 2. R-square: Variable-specific Uncertainty on Country-specific Uncertainty

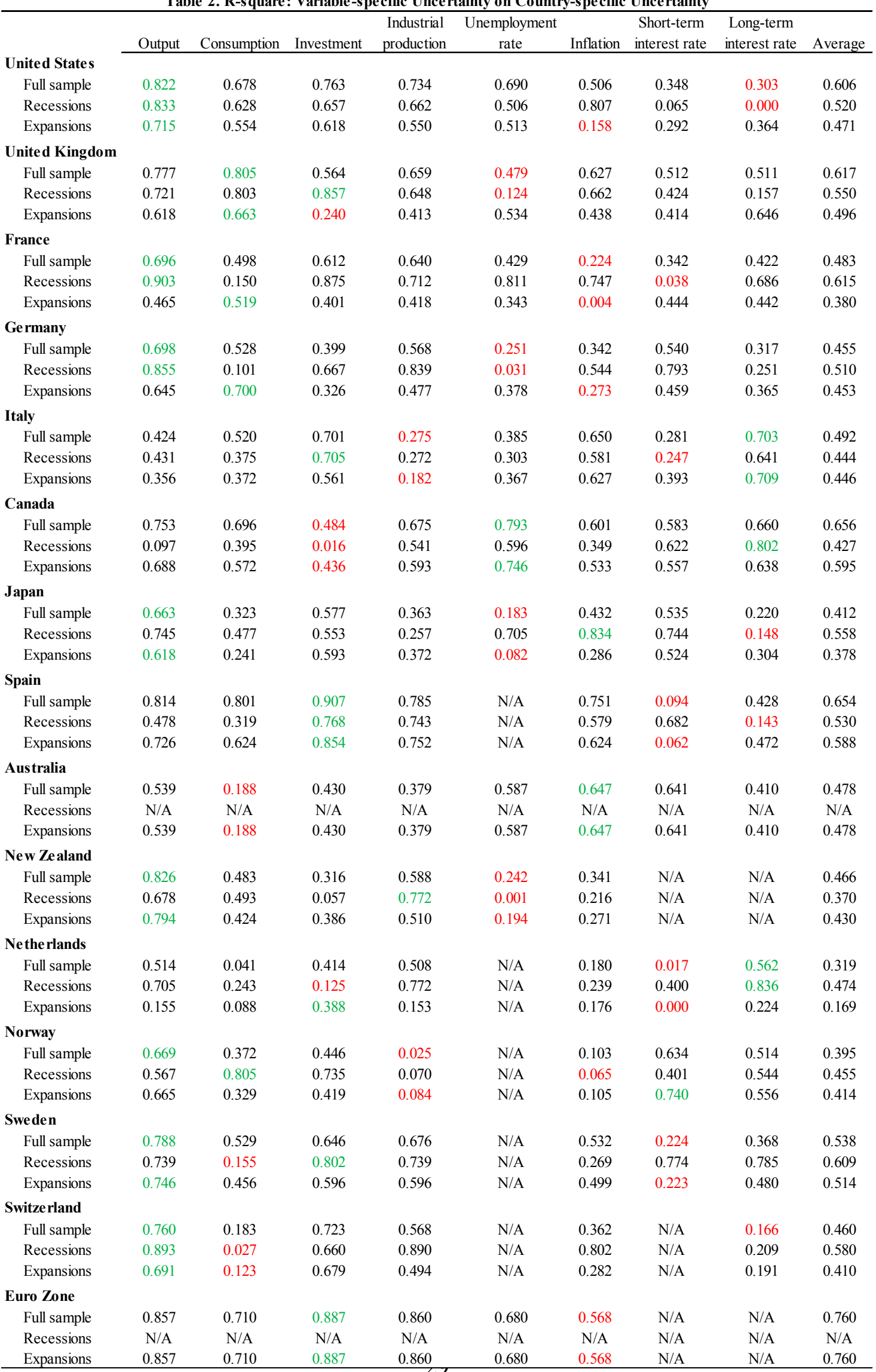


Table 2. Continued

\begin{tabular}{|c|c|c|c|c|c|c|c|c|c|}
\hline & Output & Consumption & Investment & $\begin{array}{l}\text { Industrial } \\
\text { production }\end{array}$ & $\begin{array}{c}\text { Unemployment } \\
\text { rate }\end{array}$ & Inflation & $\begin{array}{l}\text { Short-term } \\
\text { interest rate }\end{array}$ & $\begin{array}{c}\text { Long-term } \\
\text { interest rate } \\
\end{array}$ & Average \\
\hline \multicolumn{10}{|l|}{ Turkey } \\
\hline Full sample & 0.919 & 0.897 & 0.817 & 0.889 & N/A & 0.687 & 0.259 & N/A & 0.745 \\
\hline Recessions & 0.936 & 0.818 & 0.905 & 0.904 & N/A & 0.000 & 0.307 & N/A & 0.645 \\
\hline Expansions & 0.926 & 0.876 & 0.828 & 0.857 & N/A & 0.659 & 0.203 & N/A & 0.725 \\
\hline \multicolumn{10}{|l|}{ Argentina } \\
\hline Full sample & 0.824 & 0.921 & 0.812 & 0.833 & N/A & 0.858 & 0.793 & N/A & 0.840 \\
\hline Recessions & 0.976 & 0.832 & 0.881 & 0.737 & N/A & 0.503 & 0.536 & N/A & 0.744 \\
\hline Expansions & 0.903 & 0.927 & 0.831 & 0.852 & N/A & 0.924 & 0.824 & N/A & 0.877 \\
\hline \multicolumn{10}{|l|}{ Brazil } \\
\hline Full sample & 0.783 & 0.808 & 0.732 & 0.535 & N/A & 0.056 & 0.201 & N/A & 0.519 \\
\hline Recessions & 0.696 & 0.805 & 0.555 & 0.466 & N/A & 0.128 & 0.458 & N/A & 0.518 \\
\hline Expansions & 0.806 & 0.816 & 0.782 & 0.555 & N/A & 0.031 & 0.136 & N/A & 0.521 \\
\hline \multicolumn{10}{|l|}{ Chile } \\
\hline Full sample & 0.786 & 0.731 & 0.392 & 0.650 & N/A & 0.405 & 0.204 & N/A & 0.528 \\
\hline Recessions & 0.143 & 0.278 & 0.816 & 0.852 & N/A & 0.244 & 0.842 & N/A & 0.529 \\
\hline Expansions & 0.748 & 0.714 & 0.207 & 0.683 & N/A & 0.211 & 0.161 & N/A & 0.454 \\
\hline \multicolumn{10}{|l|}{ Colombia } \\
\hline Full sample & 0.693 & 0.725 & 0.454 & 0.624 & N/A & 0.544 & N/A & N/A & 0.608 \\
\hline Recessions & N/A & N/A & N/A & N/A & N/A & N/A & N/A & N/A & N/A \\
\hline Expansions & 0.693 & 0.725 & 0.454 & 0.624 & N/A & 0.544 & N/A & N/A & 0.608 \\
\hline \multicolumn{10}{|l|}{ Mexico } \\
\hline Full sample & 0.832 & 0.719 & 0.612 & 0.739 & N/A & 0.507 & 0.132 & N/A & 0.590 \\
\hline Recessions & 0.852 & 0.652 & 0.012 & 0.676 & N/A & 0.372 & 0.555 & N/A & 0.520 \\
\hline Expansions & 0.728 & 0.554 & 0.385 & 0.609 & N/A & 0.560 & 0.287 & N/A & 0.521 \\
\hline \multicolumn{10}{|l|}{ Peru } \\
\hline Full sample & 0.658 & 0.840 & 0.770 & N/A & N/A & 0.459 & N/A & N/A & 0.682 \\
\hline Recessions & 0.689 & 0.918 & 0.933 & N/A & N/A & 0.676 & N/A & N/A & 0.804 \\
\hline Expansions & 0.711 & 0.850 & 0.736 & N/A & N/A & 0.391 & N/A & N/A & 0.672 \\
\hline \multicolumn{10}{|l|}{ Venezuela } \\
\hline Full sample & 0.898 & 0.566 & 0.609 & N/A & N/A & 0.092 & 0.785 & N/A & 0.590 \\
\hline Recessions & 0.901 & 0.443 & 0.917 & N/A & N/A & 0.107 & 0.922 & N/A & 0.658 \\
\hline Expansions & 0.883 & 0.574 & 0.696 & N/A & N/A & 0.076 & 0.742 & N/A & 0.594 \\
\hline \multicolumn{10}{|l|}{ Taiwan } \\
\hline Full sample & 0.766 & 0.744 & 0.694 & 0.755 & 0.873 & 0.508 & 0.138 & 0.569 & 0.631 \\
\hline Recessions & 0.864 & 0.752 & 0.721 & 0.959 & 0.667 & 0.745 & 0.910 & 0.708 & N/A \\
\hline Expansions & 0.679 & 0.687 & 0.637 & 0.685 & 0.823 & 0.396 & 0.132 & 0.320 & 0.545 \\
\hline \multicolumn{10}{|l|}{ Hong Kong } \\
\hline Full sample & 0.807 & 0.707 & 0.779 & 0.716 & 0.907 & 0.694 & 0.705 & 0.139 & 0.682 \\
\hline Recessions & 0.806 & 0.688 & 0.858 & 0.794 & 0.335 & 0.826 & 0.858 & 0.009 & 0.647 \\
\hline Expansions & 0.807 & 0.598 & 0.677 & 0.682 & 0.899 & 0.521 & 0.465 & 0.245 & 0.612 \\
\hline \multicolumn{10}{|l|}{ India } \\
\hline Full sample & 0.435 & N/A & 0.357 & 0.183 & N/A & 0.281 & 0.117 & 0.042 & 0.236 \\
\hline Recessions & N/A & N/A & N/A & N/A & N/A & N/A & N/A & N/A & N/A \\
\hline Expansions & 0.435 & N/A & 0.357 & 0.183 & N/A & 0.281 & 0.117 & 0.042 & 0.236 \\
\hline \multicolumn{10}{|l|}{ Indonesia } \\
\hline Full sample & 0.927 & 0.900 & 0.888 & 0.803 & N/A & 0.886 & 0.803 & 0.229 & 0.777 \\
\hline Recessions & 0.439 & 0.289 & 0.272 & 0.013 & N/A & 0.261 & 0.703 & 0.648 & 0.375 \\
\hline Expansions & 0.882 & 0.810 & 0.852 & 0.781 & N/A & 0.789 & 0.760 & 0.351 & 0.746 \\
\hline South Kore a & & & & & & & & & \\
\hline Full sample & 0.894 & 0.925 & 0.904 & 0.537 & 0.884 & 0.872 & 0.727 & 0.210 & 0.744 \\
\hline Recessions & 0.611 & 0.560 & 0.607 & 0.338 & 0.723 & 0.641 & 0.335 & 0.310 & 0.516 \\
\hline Expansions & 0.875 & 0.920 & 0.880 & 0.569 & 0.861 & 0.840 & 0.654 & 0.085 & 0.711 \\
\hline Malaysia & & & & & & & & & \\
\hline Full sample & 0.835 & 0.778 & 0.727 & 0.620 & N/A & 0.363 & 0.383 & 0.628 & 0.619 \\
\hline Recessions & 0.826 & 0.706 & 0.866 & 0.142 & N/A & 0.395 & 0.613 & 0.919 & 0.638 \\
\hline Expansions & 0.789 & 0.778 & 0.727 & 0.617 & N/A & 0.229 & 0.333 & 0.535 & 0.573 \\
\hline Philippines & & & & & & & & & \\
\hline Full sample & 0.762 & 0.764 & 0.536 & 0.713 & N/A & 0.109 & 0.001 & N/A & 0.481 \\
\hline Recessions & N/A & N/A & N/A & N/A & N/A & N/A & N/A & N/A & N/A \\
\hline Expansions & 0.762 & 0.764 & 0.536 & 0.713 & N/A & 0.109 & 0.001 & N/A & 0.481 \\
\hline China & & & & & & & & & \\
\hline Full sample & 0.377 & 0.491 & 0.407 & 0.777 & N/A & 0.623 & N/A & 0.671 & 0.558 \\
\hline Recessions & $\mathrm{N} / \mathrm{A}$ & N/A & N/A & N/A & N/A & N/A & N/A & N/A & $\mathrm{N} / \mathrm{A}$ \\
\hline Expansions & 0.377 & 0.491 & 0.407 & 0.777 & N/A & 0.623 & N/A & 0.671 & 0.558 \\
\hline
\end{tabular}


Table 2. Continued

\begin{tabular}{|c|c|c|c|c|c|c|c|c|c|}
\hline & Output & Consumption & Investment & $\begin{array}{l}\text { Industrial } \\
\text { production }\end{array}$ & $\begin{array}{l}\text { Unemployment } \\
\text { rate }\end{array}$ & Inflation & $\begin{array}{l}\text { Short-term } \\
\text { interest rate }\end{array}$ & $\begin{array}{l}\text { Long-term } \\
\text { interest rate }\end{array}$ & Average \\
\hline \multicolumn{10}{|l|}{ Singapore } \\
\hline Full sample & 0.713 & 0.543 & 0.559 & 0.438 & N/A & 0.375 & 0.208 & 0.280 & 0.445 \\
\hline Expansions & 0.667 & 0.545 & 0.526 & 0.511 & N/A & 0.350 & 0.167 & 0.254 & 0.431 \\
\hline \multicolumn{10}{|l|}{ Thailand } \\
\hline Expansions & 0.849 & 0.766 & 0.482 & 0.529 & N/A & 0.146 & 0.000 & 0.092 & 0.409 \\
\hline \multicolumn{10}{|l|}{ Russia } \\
\hline Full sample & 0.902 & 0.894 & 0.945 & 0.944 & N/A & 0.527 & N/A & $\mathrm{N} / \mathrm{A}$ & 0.842 \\
\hline Recessions & 0.920 & 0.894 & 0.931 & 0.944 & N/A & 0.022 & N/A & N/A & 0.742 \\
\hline Expansions & 0.575 & 0.732 & 0.896 & 0.885 & N/A & 0.794 & N/A & N/A & 0.776 \\
\hline \multicolumn{10}{|l|}{ Ukraine } \\
\hline Full sample & 0.951 & 0.938 & 0.827 & 0.893 & N/A & 0.145 & N/A & N/A & 0.751 \\
\hline Recessions & 0.977 & 0.962 & 0.929 & 0.961 & N/A & 0.057 & N/A & N/A & 0.777 \\
\hline Expansions & 0.936 & 0.923 & 0.811 & 0.844 & N/A & 0.262 & N/A & N/A & 0.755 \\
\hline \multicolumn{10}{|c|}{ Czech Republic } \\
\hline Full sample & 0.869 & 0.880 & 0.874 & 0.897 & N/A & 0.656 & N/A & 0.479 & 0.776 \\
\hline Recessions & 0.934 & 0.878 & 0.865 & 0.902 & N/A & 0.823 & N/A & 0.652 & 0.842 \\
\hline Expansions & 0.808 & 0.876 & 0.888 & 0.912 & N/A & 0.792 & N/A & 0.297 & 0.762 \\
\hline Expansions & 0.876 & 0.739 & N/A & 0.754 & N/A & 0.936 & N/A & N/A & 0.826 \\
\hline \multicolumn{10}{|l|}{ Latvia } \\
\hline Full sample & 0.868 & N/A & 0.504 & 0.862 & N/A & 0.913 & N/A & N/A & 0.787 \\
\hline Recessions & 0.586 & N/A & 0.526 & 0.207 & N/A & 0.504 & N/A & N/A & 0.456 \\
\hline Expansions & 0.790 & N/A & 0.467 & 0.842 & N/A & 0.909 & N/A & N/A & 0.752 \\
\hline \multicolumn{10}{|l|}{ Hungary } \\
\hline Full sample & 0.780 & N/A & 0.026 & 0.742 & N/A & 0.079 & 0.849 & 0.693 & 0.528 \\
\hline Recessions & 0.782 & N/A & 0.095 & 0.836 & N/A & 0.075 & 0.876 & 0.902 & 0.594 \\
\hline Expansions & 0.610 & N/A & 0.004 & 0.666 & N/A & 0.010 & 0.652 & 0.301 & 0.374 \\
\hline \multicolumn{10}{|l|}{ Lithuania } \\
\hline Full sample & 0.890 & 0.902 & 0.848 & 0.798 & N/A & 0.748 & N/A & N/A & 0.837 \\
\hline Recessions & 0.235 & 0.725 & 0.339 & 0.590 & N/A & 0.000 & N/A & N/A & N/A \\
\hline Expansions & 0.867 & 0.823 & 0.766 & 0.691 & N/A & 0.881 & N/A & N/A & 0.806 \\
\hline \multicolumn{10}{|l|}{ Croatia } \\
\hline Full sample & 0.687 & 0.707 & 0.808 & 0.455 & N/A & 0.390 & N/A & N/A & 0.609 \\
\hline Recessions & 0.791 & 0.672 & 0.802 & 0.394 & N/A & 0.239 & N/A & N/A & 0.580 \\
\hline Expansions & 0.784 & 0.918 & 0.980 & 0.948 & N/A & 0.955 & N/A & N/A & 0.917 \\
\hline \multicolumn{10}{|l|}{ Slovenia } \\
\hline Full sample & 0.853 & 0.032 & 0.842 & 0.468 & N/A & 0.689 & N/A & N/A & 0.577 \\
\hline
\end{tabular}

Note : Each cell presents the R-square of the regressions of respective variable-specific uncertainty on country-specific uncertainty measures. Recession episodes are from Claessens, Kose, Ozturk, Terrones (2016, forthcoming). The last column presents the average of the R-square in each economy. Numbers in red are the smallest values and numbers in green are the largest values in the row they stand. 
Table 3. R-s quare: Country-specific Uncertainty on Global Uncertainty

\begin{tabular}{|c|c|c|c|c|c|c|}
\hline & \multicolumn{2}{|c|}{ Unce rtainty (total) } & \multicolumn{2}{|c|}{ Idiosyncratic Uncertainty } & \multicolumn{2}{|c|}{ Common Uncertainty } \\
\hline & $\boldsymbol{\beta}$ & $\mathbf{R}^{2}$ & $\beta$ & $\mathbf{R}^{2}$ & $\beta$ & $\mathbf{R}^{2}$ \\
\hline Estonia & $1.597 * * *$ & 0.880 & $1.369^{* * *}$ & 0.698 & $1.190 * * *$ & 0.816 \\
\hline Bulgaria & $1.396^{* * *}$ & 0.886 & $1.247 * * *$ & 0.586 & $1.012 * * *$ & 0.812 \\
\hline Lithuania & $1.351 * * *$ & 0.925 & $1.136 * * *$ & 0.686 & $1.024 * * *$ & 0.873 \\
\hline Latvia & $1.346 * * *$ & 0.904 & $1.122 * * *$ & 0.772 & $1.032 * * *$ & 0.802 \\
\hline Taiwan & $1.320 * * *$ & 0.891 & $1.228 * * *$ & 0.692 & $1.007 * * *$ & 0.875 \\
\hline Peru & $1.296^{* * *}$ & 0.694 & $1.075 * * *$ & 0.373 & $0.943 * * *$ & 0.644 \\
\hline Russia & $1.268 * * *$ & 0.836 & $1.147 * * *$ & 0.481 & $0.922 * * *$ & 0.678 \\
\hline Philippines & $1.255^{* * *}$ & 0.857 & $1.216^{* * *}$ & 0.490 & $0.913 * * *$ & 0.780 \\
\hline United States & $1.212^{* * *}$ & 0.782 & $1.249 * * *$ & 0.686 & $0.808 * * *$ & 0.670 \\
\hline Canada & $1.211^{* * *}$ & 0.677 & $1.008 * * *$ & 0.488 & $0.891 * * *$ & 0.703 \\
\hline United Kingdom & $1.210 * * *$ & 0.711 & $1.230 * * *$ & 0.654 & $0.844 * * *$ & 0.702 \\
\hline New Zealand & $1.161 * * *$ & 0.798 & $1.071 * * *$ & 0.557 & $0.820 * * *$ & 0.678 \\
\hline Euro Zone & $1.144^{* * *}$ & 0.679 & $1.329 * * *$ & 0.623 & $0.863 * * *$ & 0.618 \\
\hline Czech Republic & $1.122 * * *$ & 0.906 & $0.866^{* * *}$ & 0.706 & $0.889 * * *$ & 0.817 \\
\hline Mexico & $1.108 * * *$ & 0.789 & $1.132 * * *$ & 0.642 & $0.801 * * *$ & 0.819 \\
\hline Romania & $1.104 * * *$ & 0.803 & $0.902 * * *$ & 0.483 & $0.761 * * *$ & 0.687 \\
\hline Turkey & $1.081 * * *$ & 0.849 & $0.800 * * *$ & 0.386 & $0.947 * * *$ & 0.887 \\
\hline China & $1.071 * * *$ & 0.428 & $1.334 * * *$ & 0.418 & $0.678 * * *$ & 0.354 \\
\hline Hong Kong & $1.047 * * *$ & 0.435 & $0.844 * * *$ & 0.306 & $0.814 * * *$ & 0.476 \\
\hline Colombia & $1.043 * * *$ & 0.724 & $0.954 * * *$ & 0.538 & $0.773 * * *$ & 0.562 \\
\hline Chile & $1.023 * * *$ & 0.724 & $1.152 * * *$ & 0.596 & $0.730 * * *$ & 0.685 \\
\hline Sweden & $1.000 * * *$ & 0.517 & $0.832 * * *$ & 0.328 & $0.819 * * *$ & 0.592 \\
\hline Singapore & $0.988 * * *$ & 0.708 & $0.891 * * *$ & 0.494 & $0.739 * * *$ & 0.721 \\
\hline Brazil & $0.970 * * *$ & 0.731 & $0.947 * * *$ & 0.535 & $0.747 * * *$ & 0.800 \\
\hline Australia & $0.968^{* * *}$ & 0.566 & $1.071^{* * *}$ & 0.534 & $0.660 * * *$ & 0.592 \\
\hline Switzerland & $0.961^{* * *}$ & 0.808 & $0.856^{* * *}$ & 0.506 & $0.769 * * *$ & 0.780 \\
\hline Japan & $0.954 * * *$ & 0.692 & $0.867 * * *$ & 0.465 & $0.747 * * *$ & 0.671 \\
\hline Germany & $0.946^{* * *}$ & 0.625 & $0.765^{* * *}$ & 0.457 & $0.723 * * *$ & 0.636 \\
\hline Ukraine & $0.911^{* * *}$ & 0.544 & $0.863^{* * *}$ & 0.269 & $0.649 * * *$ & 0.428 \\
\hline France & $0.903^{* * *}$ & 0.571 & $0.740 * * *$ & 0.385 & $0.717 * * *$ & 0.584 \\
\hline Slovakia & $0.890 * * *$ & 0.872 & $0.856^{* * *}$ & 0.489 & $0.698 * * *$ & 0.837 \\
\hline Croatia & $0.885^{* * *}$ & 0.711 & $0.588^{* * *}$ & 0.274 & $0.799 * * *$ & 0.651 \\
\hline Spain & $0.860 * * *$ & 0.378 & $0.830 * * *$ & 0.397 & $0.660 * * *$ & 0.366 \\
\hline Hungary & $0.783^{* * *}$ & 0.819 & $0.933^{* * *}$ & 0.571 & $0.614 * * *$ & 0.833 \\
\hline Slovenia & $0.722 * * *$ & 0.537 & $0.833 * * *$ & 0.441 & $0.562 * * *$ & 0.452 \\
\hline Italy & $0.702 * * *$ & 0.315 & $0.584 * * *$ & 0.221 & $0.609 * * *$ & 0.388 \\
\hline Poland & $0.632 * * *$ & 0.788 & $0.899 * * *$ & 0.616 & $0.391 * * *$ & 0.775 \\
\hline Malaysia & $0.605 * * *$ & 0.180 & $0.553 * * *$ & 0.156 & $0.477 * * *$ & 0.191 \\
\hline Netherlands & $0.541 * * *$ & 0.451 & $0.648 * * *$ & 0.234 & $0.406 * * *$ & 0.504 \\
\hline South Korea & $0.500 * * *$ & 0.090 & $0.495 * * *$ & 0.109 & $0.400 * * *$ & 0.106 \\
\hline India & $0.460 * * *$ & 0.432 & $0.292 * * *$ & 0.053 & $0.373 * * *$ & 0.504 \\
\hline Norway & $0.452 * * *$ & 0.215 & $0.356 * * *$ & 0.054 & $0.382 * * *$ & 0.407 \\
\hline Argentina & $0.412 * * *$ & 0.076 & $0.311^{* * *}$ & 0.048 & $0.352 * * *$ & 0.092 \\
\hline Thailand & $0.350 * * *$ & 0.079 & $0.327 * * *$ & 0.049 & $0.300 * * *$ & 0.110 \\
\hline Indonesia & $0.208 * * *$ & 0.017 & $0.276^{* * *}$ & 0.029 & $0.163 * * *$ & 0.021 \\
\hline Venezuela & 0.039 & 0.001 & $0.183 * * *$ & 0.026 & -0.022 & 0.000 \\
\hline
\end{tabular}

Note: Economies are sorted with respect to their estimated coefficients in uncertainty (total). Each result is based on bivariate regressions of country-specific uncertainty on global uncertainty. *** indicates significance at 1 percent level. 
Table 4. Corre lations of Uncertainty Measures: United States

\begin{tabular}{|c|c|c|c|c|c|c|c|c|}
\hline & $\begin{array}{c}\text { Country- } \\
\text { specific } \\
\text { uncertainty }\end{array}$ & $\begin{array}{c}\text { Common } \\
\text { uncertainty }\end{array}$ & $\begin{array}{c}\text { Idiosyncratic } \\
\text { uncertainty }\end{array}$ & $\begin{array}{c}\text { Economic } \\
\text { policy } \\
\text { uncertainty }\end{array}$ & $\begin{array}{c}\text { News-based } \\
\text { policy } \\
\text { uncertainty }\end{array}$ & $\begin{array}{c}\text { Jurado et al. } \\
(2015)\end{array}$ & $\begin{array}{r}\text { Scotti } \\
(2016) \\
\end{array}$ & $\mathrm{VXO}$ \\
\hline Country-specific uncertainty & 1.00 & & & & & & & \\
\hline Common uncertainty & 0.94 & 1.00 & & & & & & \\
\hline Idiosyncratic uncertainty & 0.80 & 0.54 & 1.00 & & & & & \\
\hline Economic policy uncertainty & 0.18 & 0.05 & 0.36 & 1.00 & & & & \\
\hline News-based policy uncertainty & 0.19 & 0.07 & 0.35 & 0.90 & 1.00 & & & \\
\hline Jurado et al. (2015) & 0.79 & 0.75 & 0.59 & 0.28 & 0.27 & 1.00 & & \\
\hline Scotti (2016) & 0.38 & 0.30 & 0.44 & 0.22 & 0.26 & 0.58 & 1.00 & \\
\hline VXO & 0.54 & 0.48 & 0.49 & 0.40 & 0.49 & 0.60 & 0.51 & 1.00 \\
\hline
\end{tabular}

Note: News-based policy uncertainty and economic policy uncertainty measureas are from the policy uncertainty website of Baker, Bloom, and Davis (2016). All correlations except those with Scotti (2016) cover 1989M11-2014M7 period and correlations with Scotti (2016) cover 2003M52014M7 period. 

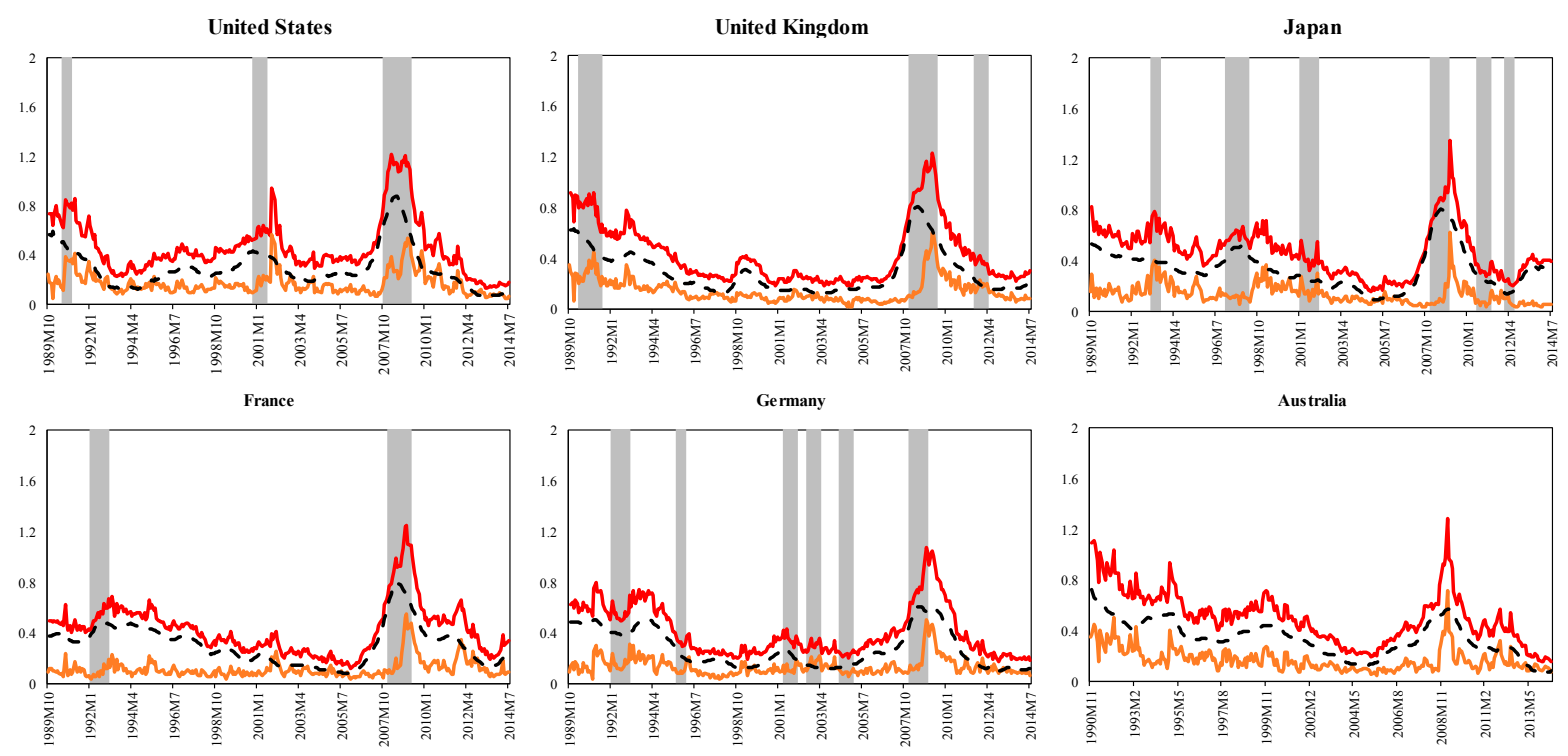

Italy

Canada
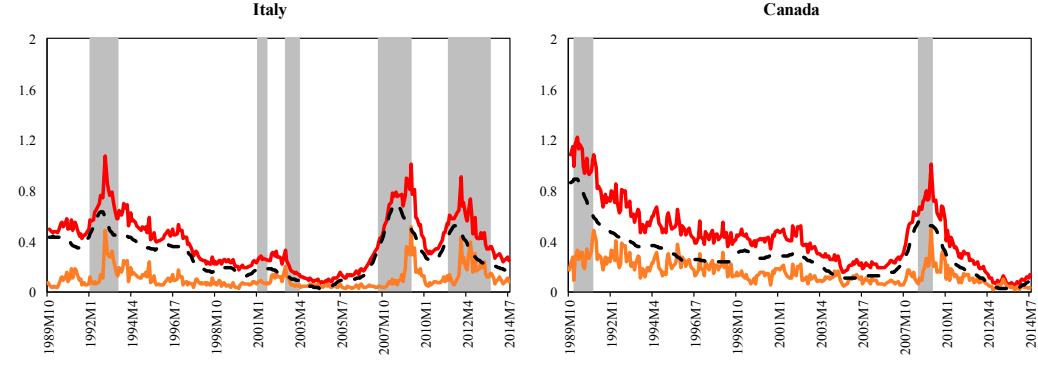

New Zealand
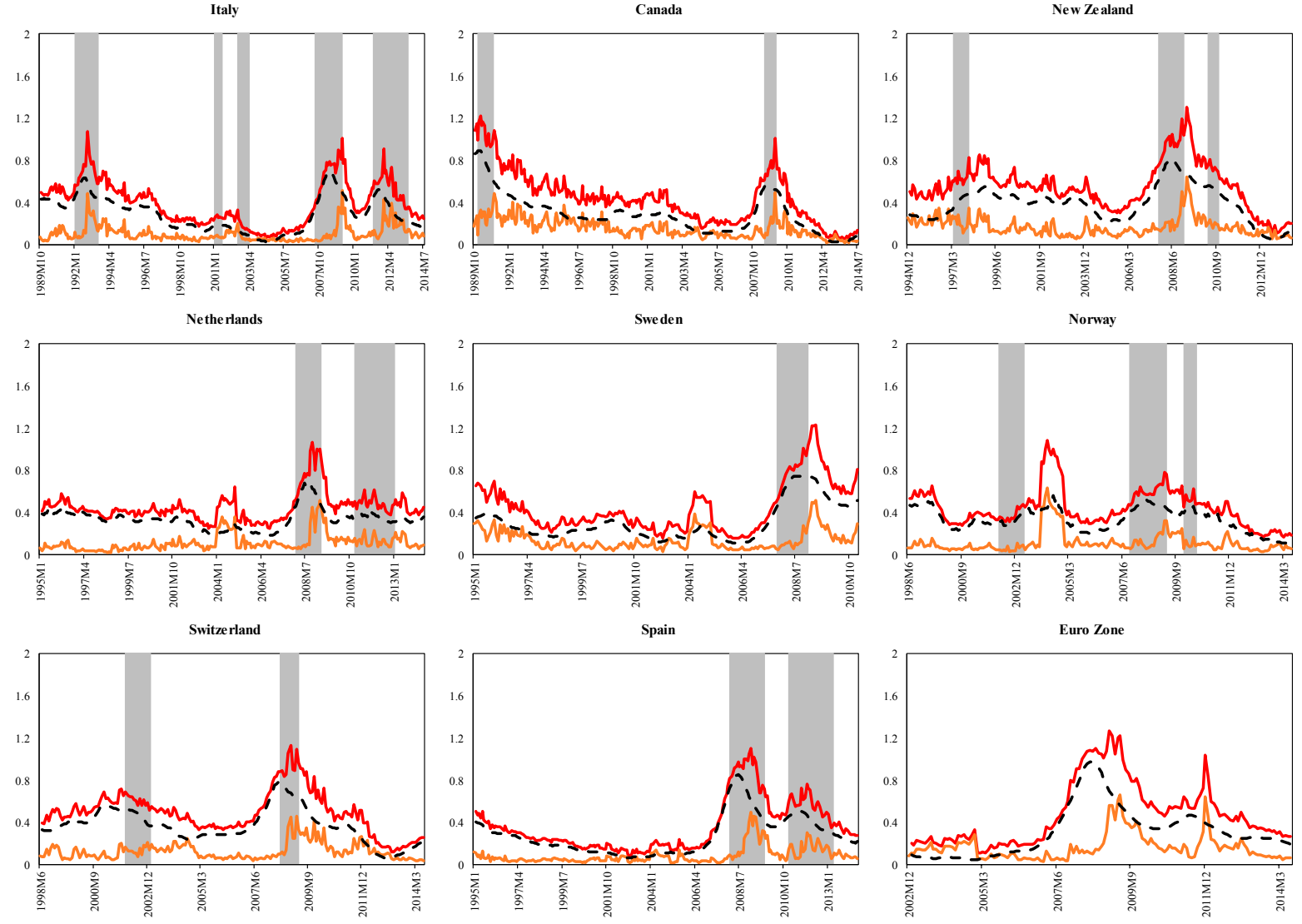

— Idiosyncratic Uncertainty - - - Common Uncertainty

Country-specific Uncertainty

Figure 1. Country-Specific Uncertainty

Note: Country-specific uncertainty is the sum of idiosyncratic and common uncertainty. Gray bars indicate the period of recessions as identified in Claessens, et. al. (2016, forthcoming). 

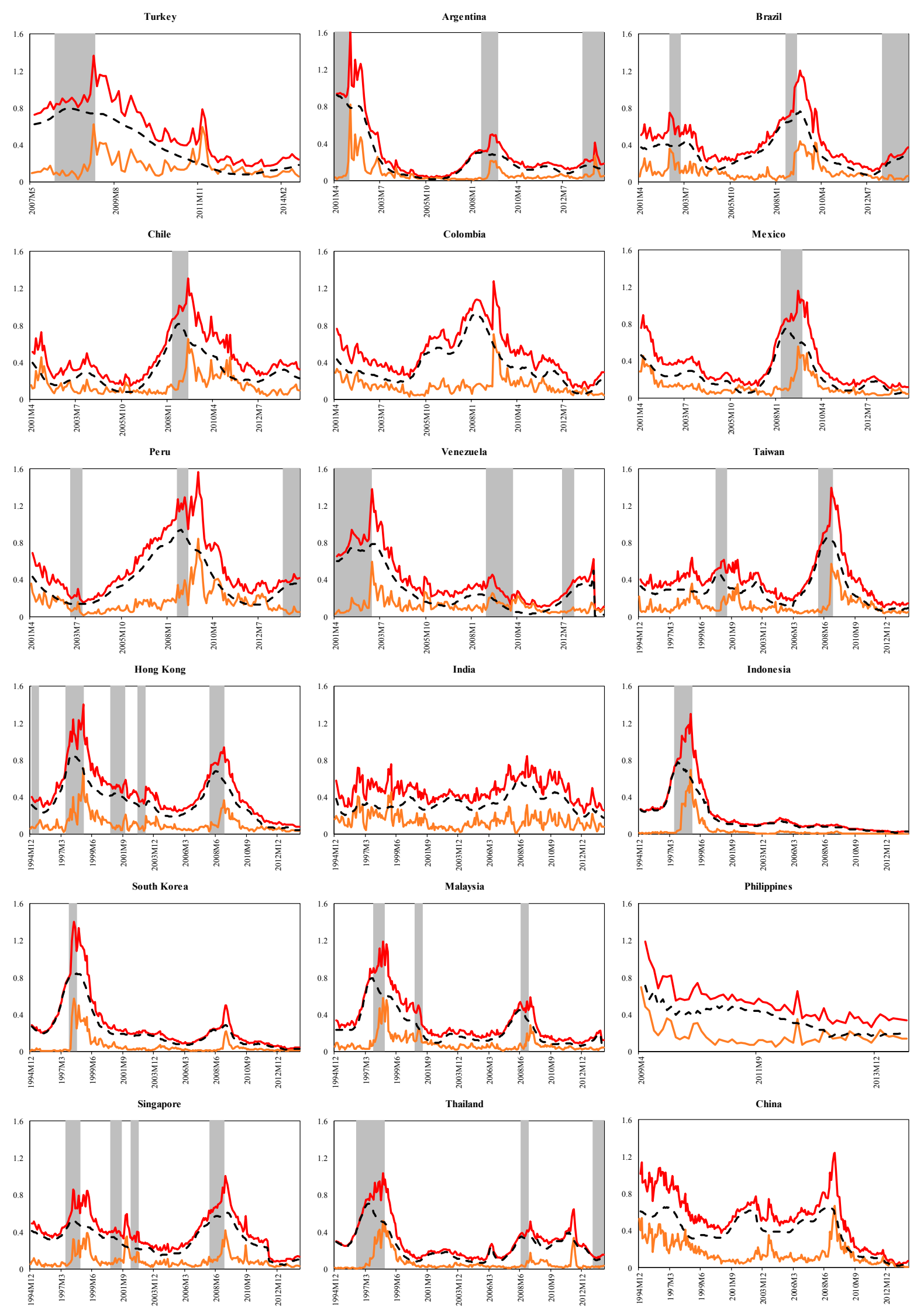

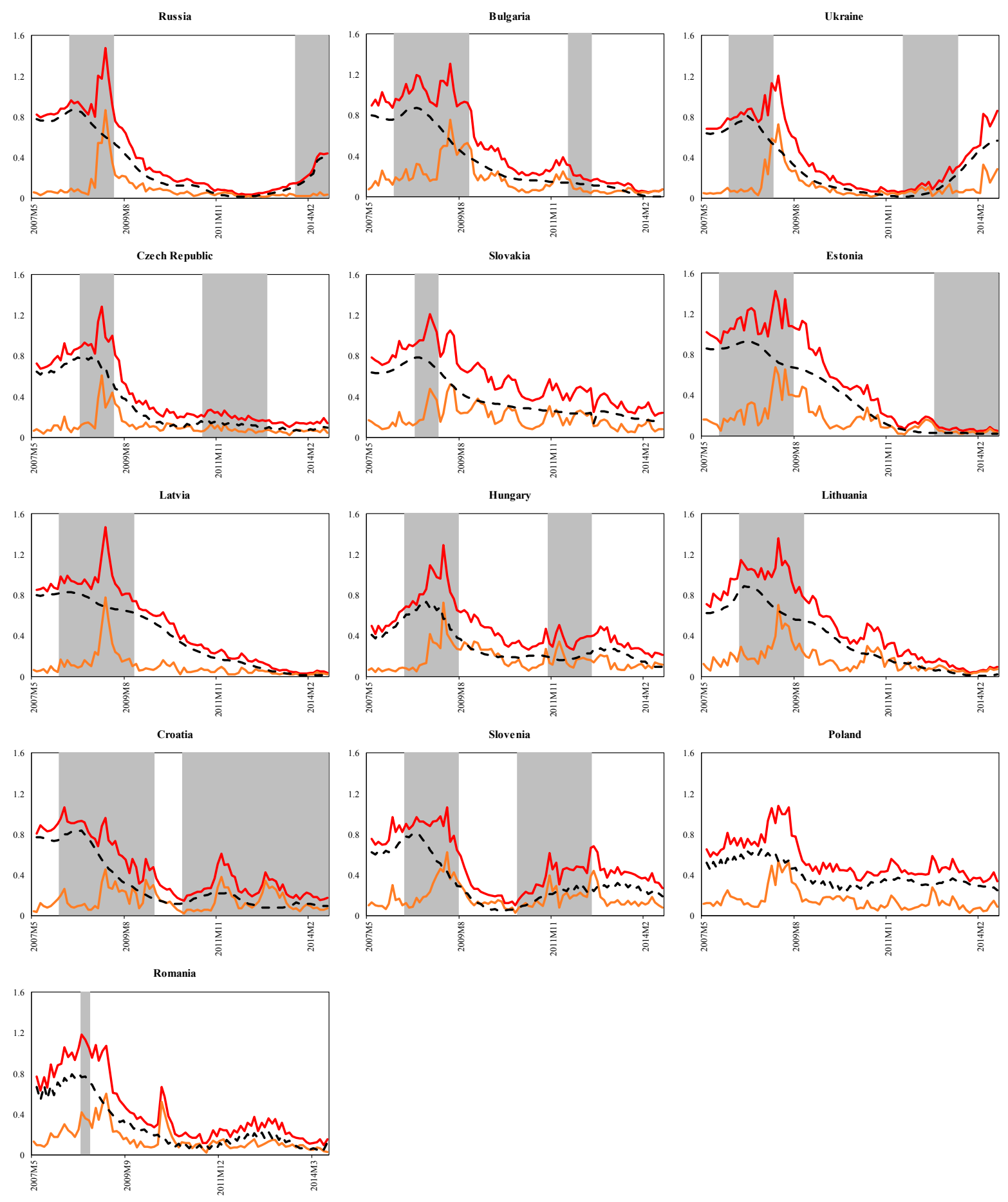

_ Idiosyncratic Uncertainty - - - Common Uncertainty

Figure 1. Country-Specific Uncertainty (continued) 


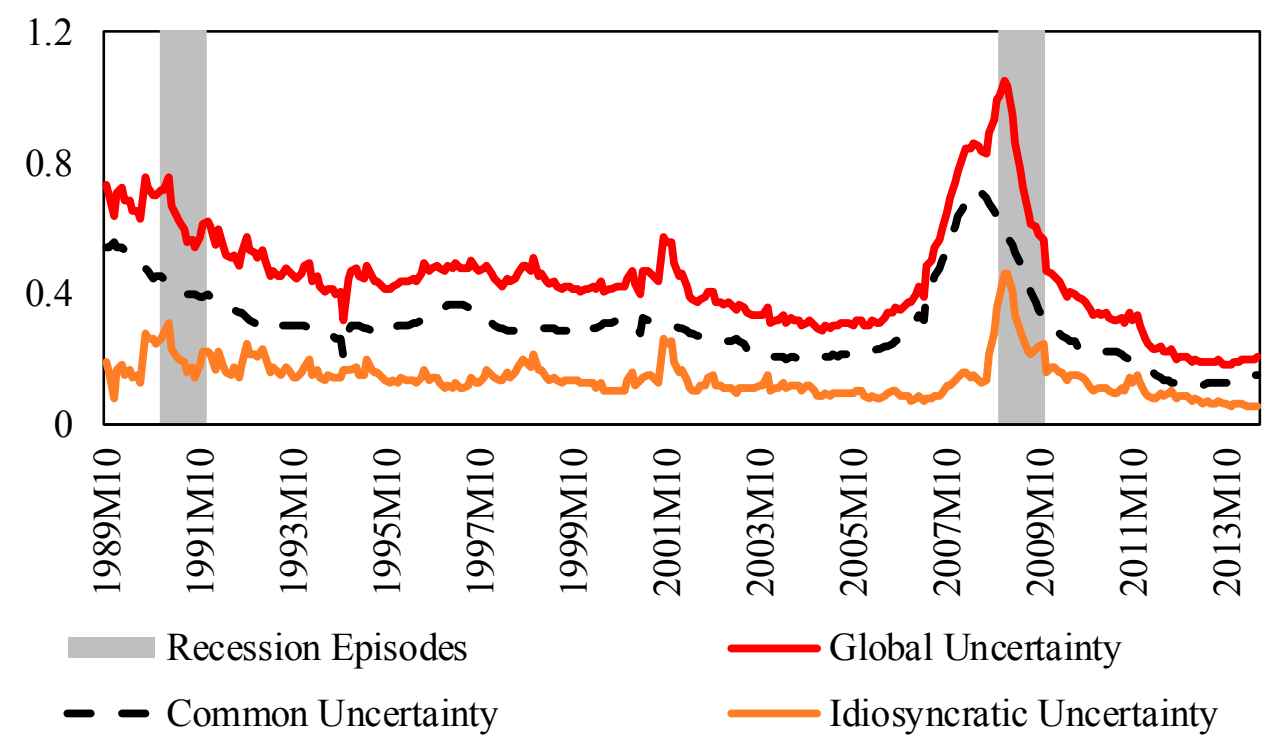

Figure 2. Global Uncertainty

Note: Each line presents the PPP-weighted average of the respective measure for 46 economies. Gray bars present the global recession episodes identified by Kose and Terrones (2015). 

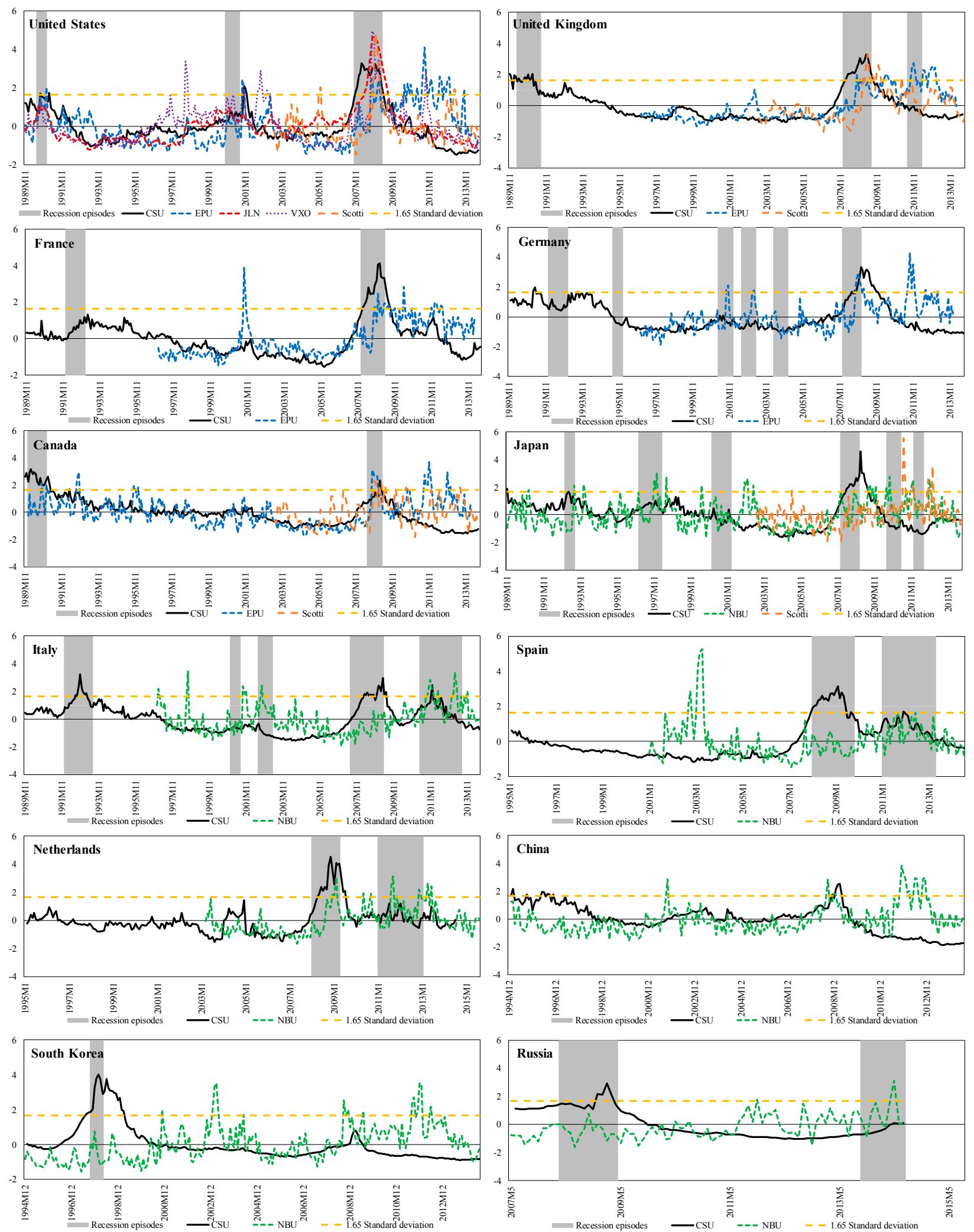

Figure 3. Comparison of Uncertainty Measures

Note: Each uncertainty measure is standardized by subtracting the mean and dividing by the standard deviation. CSU = country-specific uncertainty, JLN=uncertainty measure from Jurado et al (2015), EPU=economic policy uncertainty (Baker et al, 2016), NBU=news-based uncertainty (Baker et al, 2016), Scotti=Monthly average of ex-ante daily uncertainy (Scotti, 2016). 
A. Industrial Production
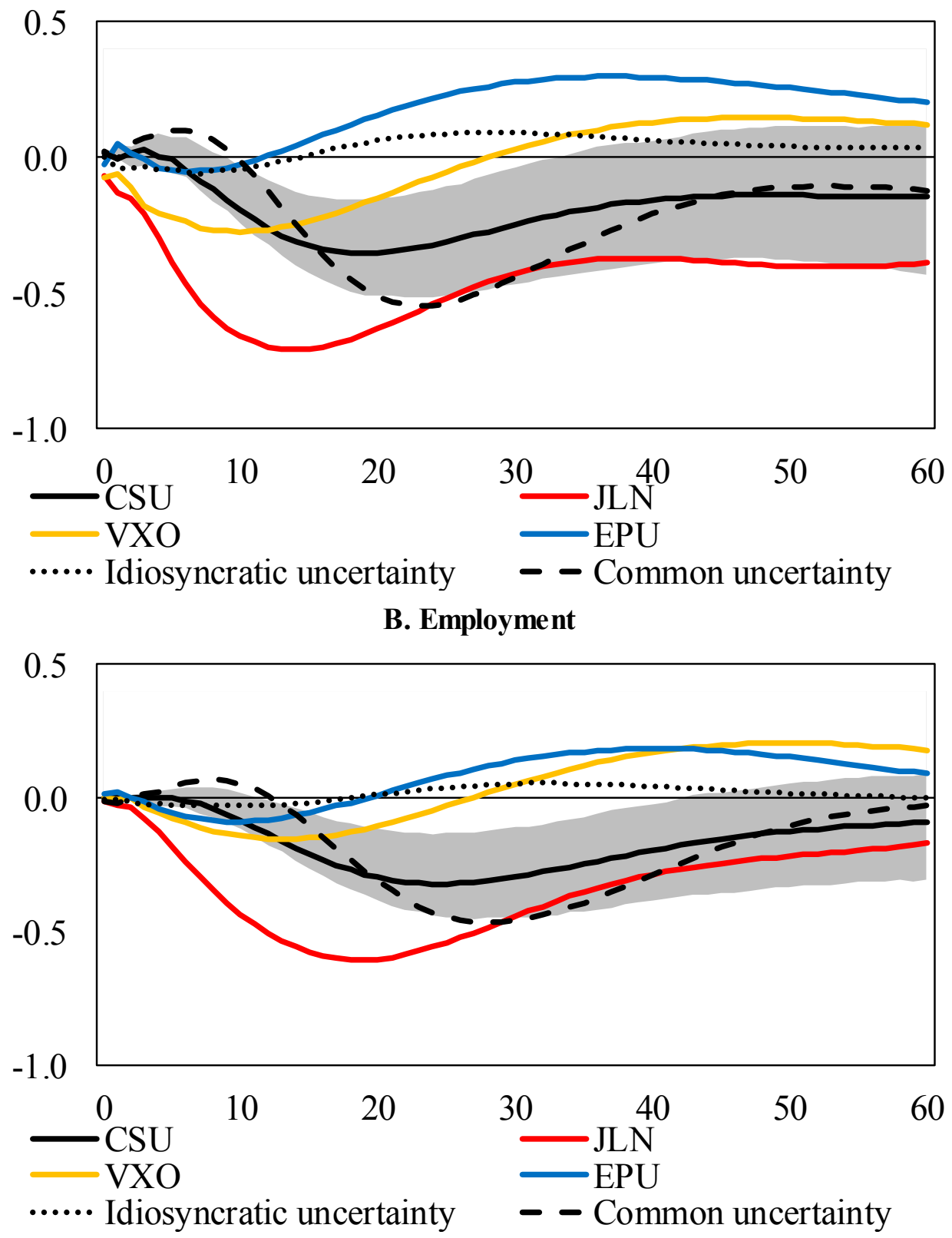

Figure 4. Responses to Uncertainty Shocks

Note : Panel A (Panel B) plots the responses of industrial production (employment) to uncertainty shocks identified recursively in eight-variable VAR system estimated separately for each of the uncertainty measures. CSU=country-specific uncertainty; JLN=uncertainty estimate from Jurado et. al (2015), EPU= economic policy uncertainty estimate from Baker et. al (2016). Dotted (dashed) line is the response to the forecast disagreement shocks, where CSU is replaced with idiosyncratic uncertainty (common uncertainty) component. Shaded regions present 64 percent confidence intervals using Killian (1998) bias-corrected bootstrap. 


\section{A. Industrial Production}

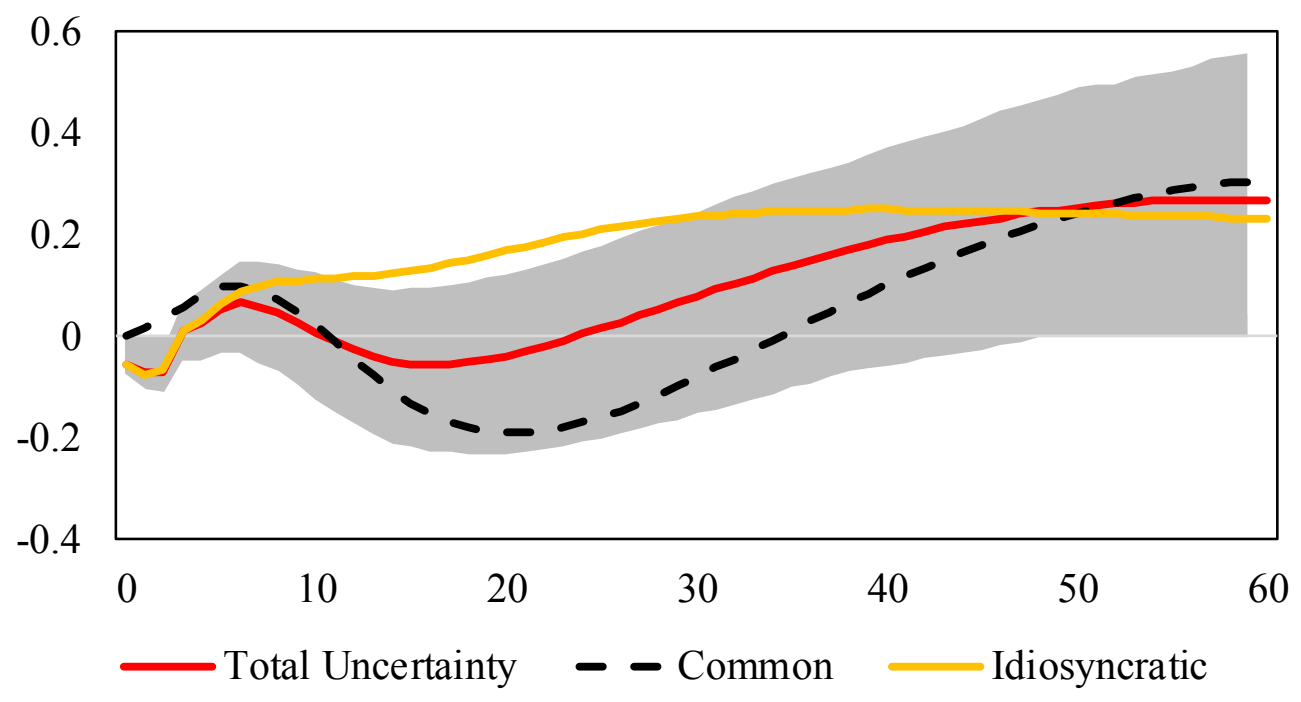

B. Une mployment

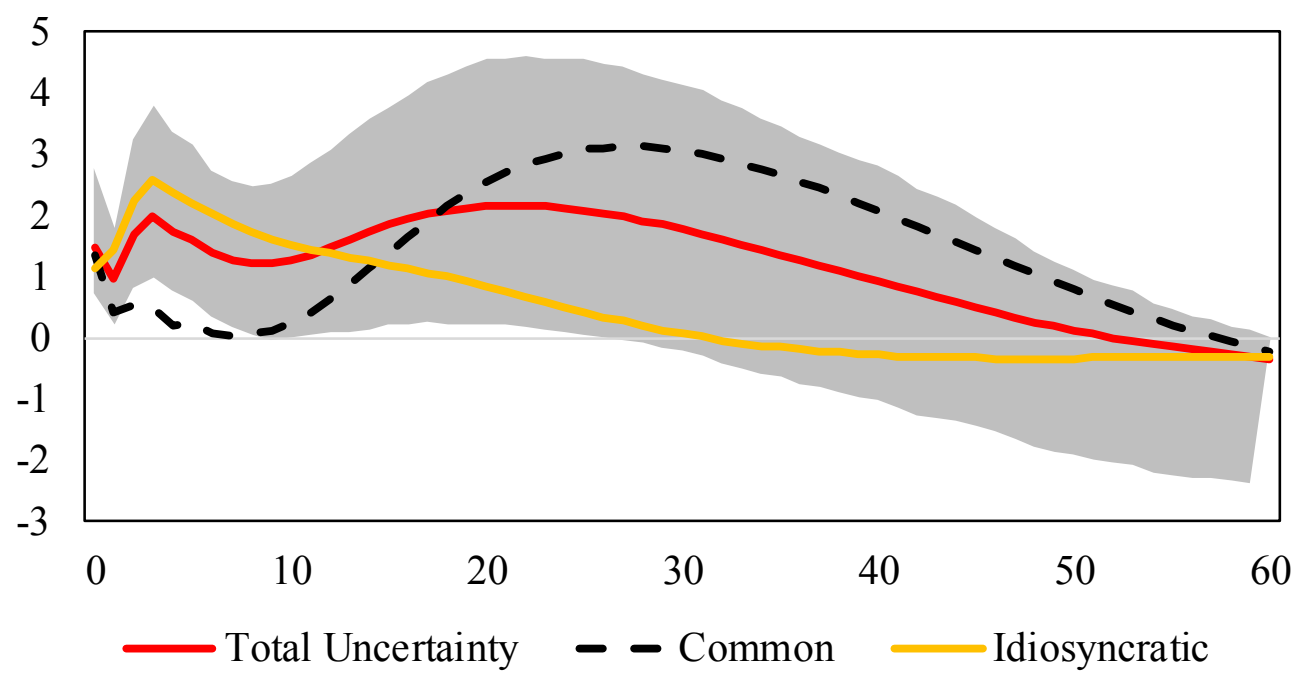

Figure 5. Responses to Global Uncertainty Shocks

Note: Panel A (Panel B) plots the responses of industrial production (unemployment rate) to uncertainty shocks identified recursively in a seven-variable VAR system estimated separately for total uncertainty and its common and idiosyncratic components. 

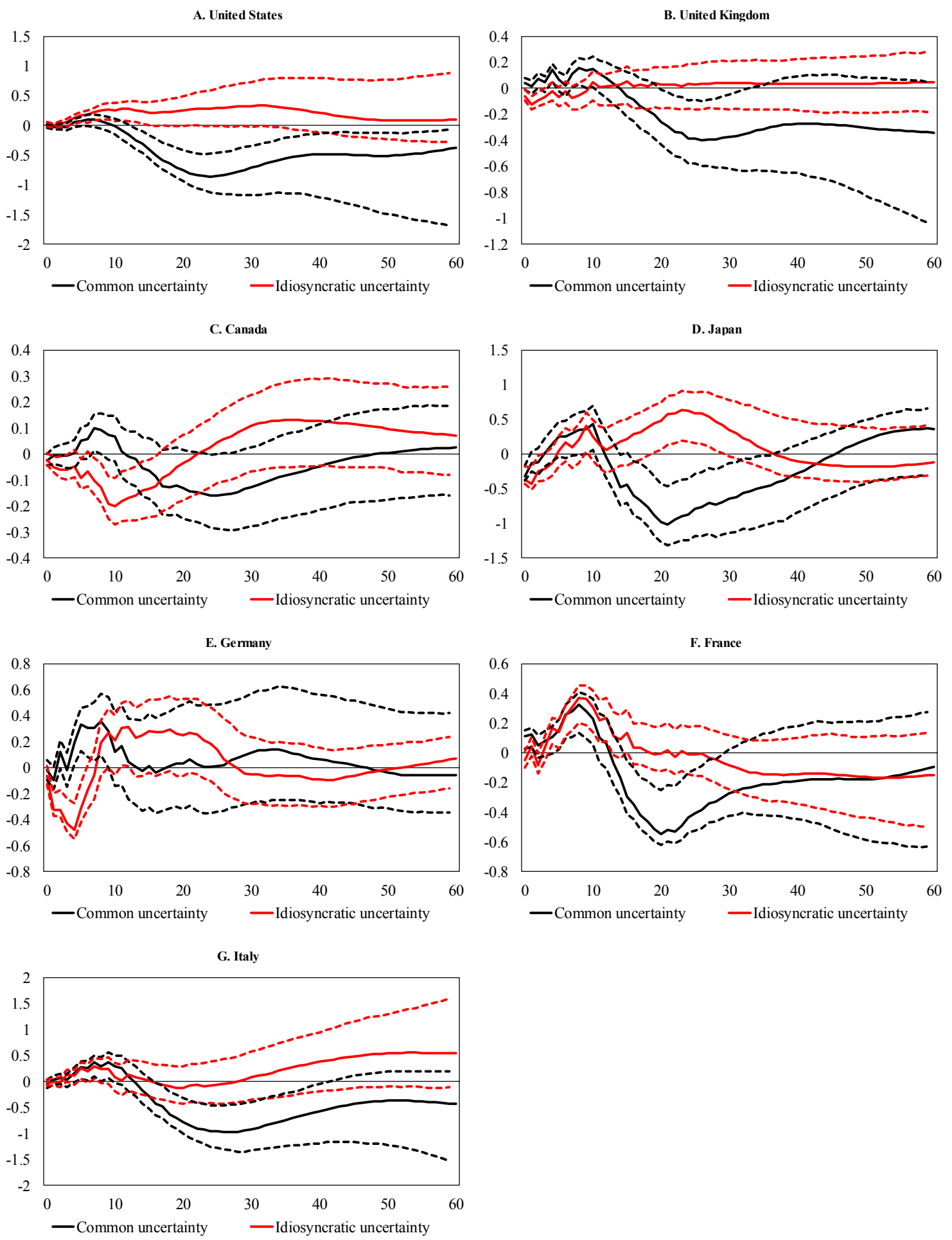

Figure 6. Response of industrial production to common and idiosyncratic uncertainty shocks

Note: Dashed lines present 64 percent confidence intervals using Killian (1998) biascorrected bootstrap. 